Aquatic Nuisance Species Research Program

Potential for Predation by Fishes to Impact Zebra Mussels Dreissena polymorpha: Insight from Bioenergetics Models

Michael A. Eggleton, Steve Miranda, and James P. Kirk

December 2003

US Army Corps of Engineers ${ }_{\circledast}$

Engineer Research and Development Center

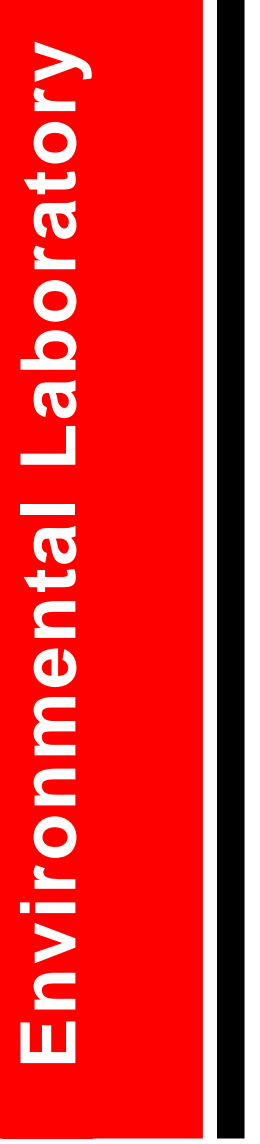




\section{Potential for Predation by Fishes to Impact Zebra Mussels Dreissena polymorpha: Insight from Bioenergetics Models}

Michael A. Eggleton

University of Oklahoma

Norman, OK 73069

Steve Miranda

Department of Wildlife and Fisheries

Mississippi State University

Starkville, MS 39762

James P. Kirk

U.S. Army Engineer Research and Development Center

Environmental Laboratory

3909 Halls Ferry Road

Vicksburg, MS 39180-6199

Final report

Approved for public release; distribution is unlimited 


\begin{abstract}
:
Bioenergetic modeling provided insight into the potential for fishes to impact zebra mussel Dreissena polymorpha populations by predation across river and lake systems in eastern North America ( $13^{\circ}$ latitude $\times 12^{\circ}$ longitude). Food consumption modeling suggested that fishes in southern latitudes consumed up to 100 percent more food than those in northern systems. Much variation in food consumption resulted from differing water temperature regimes, which presumably dictated the bioenergetic demands of fishes. The potential for fishes to impact zebra mussels was also influenced by the standing crop of different species and the fish community as a whole. Fish community structures followed predictable patterns along both longitudinal and latitudinal gradients. Multivariate analyses indicated a tendency for central and southern U.S. systems to contain greater standing crops or biomasses of fishes likely to consume zebra mussels. Though analyses indicated northern systems had greater biomasses of some potential zebra mussel predators, net biomass increases of these species was not great enough to offset the decreases in food consumption because of cooler annual water temperatures. This study generally supports the premise that fishes in more southern (including central) U.S. waters have inherently greater potential to impact zebra mussels because of community composition and bioenergetics. Our simulations provide a partial explanation of why zebra mussel invasions have not been as rapid and widespread in southern U.S. waters compared to the Great Lakes region.
\end{abstract}

DISCLAIMER: The contents of this report are not to be used for advertising, publication, or promotional purposes. Citation of trade names does not constitute an official endorsement or approval of the use of such commercial products. All product names and trademarks cited are the property of their respective owners. The findings of this report are not to be construed as an official Department of the Army position unless so designated by other authorized documents. 


\section{Contents}

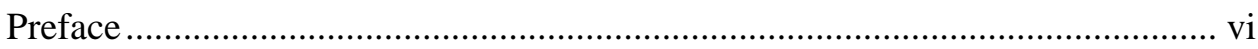

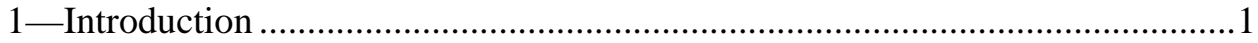

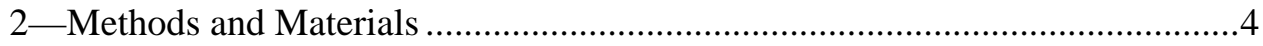

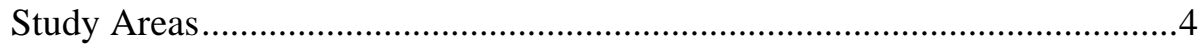

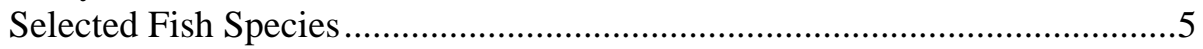

Food Consumption Model .........................................................................

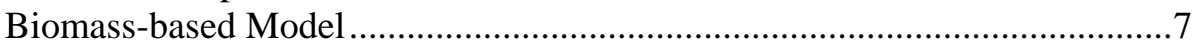

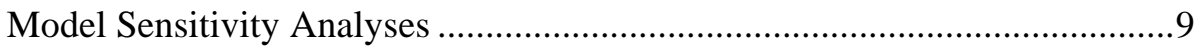

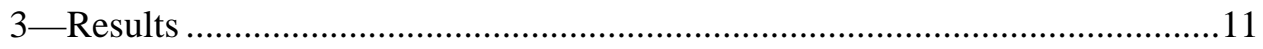

Food Consumption Model ......................................................................11

Biomass-based Food Consumption.........................................................18

Spatial Variation in Fish Communities ........................................................29

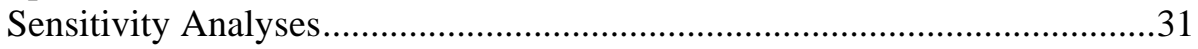

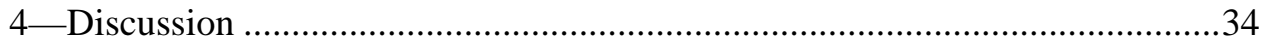

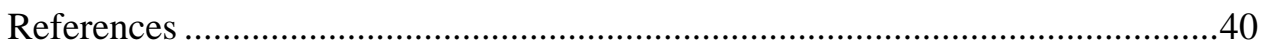

SF 298

\section{List of Figures}

Figure 1. Geographic location of the eight study areas used for food consumption modeling simulations ......................................4

Figure 2. Annual thermographs for several U.S. river and lake systems where zebra mussels are present ..................................12

Figure 3. Simulated annual food consumption of common carp from eight U.S. river and lake systems during a year of average thermal conditions

Figure 4. Simulated annual food consumption of lake sturgeon from eight U.S. river and lake systems during a year of average thermal conditions. 
Figure 5. Simulated annual food consumption of freshwater drum from eight U.S. river and lake systems during a year of average thermal conditions

Figure 6. Simulated annual food consumption of channel catfish from eight U.S. river and lake systems during a year of average thermal conditions.

Figure 7. Linear regression analysis of total fish biomass vs. latitude and longitude for 428 reservoir and river systems in the United States.

Figure 8. Linear regression analysis of biomass vs. latitude and longitude for spotted sucker from 428 reservoir and river systems in the United States

Figure 9. Linear regression analysis of biomass vs. latitude and longitude for river carpsucker from 428 reservoir and river systems in the United States .22

Figure 10. Linear regression analysis of biomass vs. latitude and longitude for redhorses from 428 reservoir and river systems in the United States

Figure 11. Linear regression analysis of biomass vs. latitude and longitude for common carp from 428 reservoir and river systems in the United States.....

Figure 12. Linear regression analysis of biomass vs. latitude and longitude for freshwater drum from 428 reservoir and river systems in the United States

Figure 13. Linear regression analysis of biomass vs. latitude and longitude for channel catfish from 428 reservoir and river systems in the United States ....

Figure 14. Linear regression analysis of biomass vs. latitude and longitude for blue catfish from 428 reservoir and river systems in the United States.

Figure 15. Linear regression analysis of biomass vs. latitude and longitude for buffalofishes from 428 reservoir and river systems in the United States.

Figure 16. Scatterplot of axis-1 and axis-2 scores from correspondence analysis of fish biomass estimates from U.S. reservoir and river systems 30

Figure 17. Scatterplot of axis-1 and axis-3 scores from correspondence analysis of fish biomass estimates from U.S. reservoir and river systems 
Figure 18. Comparison of predicted total fish biomass versus latitude curves and biomass required to maintain consumption at levels estimated for the lower Mississippi River using the Eggers model

Figure 19. Comparison of predicted biomass versus latitude curves and biomass required to maintain consumption at levels estimated for the lower Mississippi River using the Eggers model

\section{List of Tables}

Table 1. River and Lake Systems Selected for Food Consumption Modeling Simulations

Table 2. Generalized Weight-Length Regression Equations and Weight-At-Age Estimates Used for Each Species in this Evaluation .6

Table 3. Thermal Characteristics of the Eight River and Lakes Systems Used for Food Consumption Simulations .13

Table 4. Mean Proportional Increases in Annual Consumption by Target Species Averaged Across Eight River and Lake Systems.

Table 5. $\quad$ Predicted Annual Food Consumption of Selected Fish Species for Each Study System Estimated with BiomassBased Model.

Table 6. Predicted Annual Food Consumption of Selected Fish Species for Each Study Estimated with Biomass-Based Model

Table 7. Proportional Changes in Annual Consumption Based on Sensitivity Analysis of Food Consumption Modeling .................32

Table 8. Proportional Changes in Annual Consumption Based on Sensitivity Analysis of Biomass-Based Food Consumption Modeling.... 


\section{Preface}

Financial support for this study was provided by the U.S. Army Corps of Engineers (USACE) Aquatic Nuisance Species Research Program, supervised by Dr. Al Confrancesco, Chief, Environmental Resources Engineering Branch, Environmental Laboratory (EL), U.S. Army Engineer Research and Development Center (ERDC), Vicksburg, MS. Dr. K. J. Killgore, EL, ERDC, provided important impetus and early direction for this effort as did the late Mr. L. G. Sanders, EL, ERDC. The U.S. Army Engineer Districts, Vicksburg, Detroit, and Cincinnati, the National Weather Service, the National Oceanographic and Atmospheric Administration, and the U.S. Geological Survey - Upper Midwest Environmental Sciences Center provided needed water temperature data sets. The Departments of Natural Resources in West Virginia, Michigan, Wisconsin, and Ohio and the Illinois Natural History Survey supported these efforts by providing fish community and biomass information for aquatic systems in those regions.

This research was conducted and the report was written by Dr. Mike Eggleton, University of Oklahoma, Dr. Steve Miranda, Department of Wildlife and Fisheries at Mississippi State University, and Dr. Phil Kirk, EL, ERDC. Dr. Eggleton is a postdoctoral research assistant at the University of Oklahoma where he has been evaluating the anthropogenic effects upon riparian and littoral communities in a large reservoir. Dr. Miranda is an Assistant Unit Leader with the Mississippi Cooperative Fish and Wildlife Research Unit and Professor in the Department of Wildlife and Fisheries at Mississippi State University. Dr. Phil Kirk joined EL, ERDC, in 1992 and has worked on a range of fisheries issues including aquatic plant management, endangered species, and invasive aquatic organisms.

COL John W. Morris III, EN, was Commander and Executive Director of ERDC, and Dr. James R. Houston was Director of ERDC. 


\section{Introduction}

Zebra mussels Dreissena polymorpha invaded North America in the mid1980s (Nalepa and Schloesser 1993). They are perhaps the most influential animals to invade North American fresh waters (Thorp, Delong, and Casper 1998), having effects across numerous ecosystem levels (Richardson and Bartsch 1997; Mayer et al. 2000; Idrisi et al. 2001). Zebra mussels were first collected in Lake St. Clair in 1986 (Ram and McMahon 1996), spread rapidly through the Great Lakes by the early 1990s (Mills et al. 1993), and then southward through the Illinois, Mississippi, Ohio, Cumberland, Tennessee, Arkansas, and Atchafalaya Rivers by the mid-1990s (Allen, Thompson, and Ramcharan 1999).

Zebra mussels occur patchily in most systems with the greatest densities occurring on harder, exposed substrates. Densities commonly range from 2,000 to 100,000 mussels $\cong \mathrm{m}^{-2}$ (Nalepa and Schloesser 1993), though densities up to 340,000 mussels $\cong \mathrm{m}^{-2}$ have been reported from western Lake Erie (Leach 1993). Greater densities have been reported anecdotally from other systems. At the southern end of their range, the lower Mississippi River, densities are modest, typically on the order of hundreds of mussels $\cong \mathrm{m}^{-2}$ (Personal Communication D. Miller, U.S. Army Corps of Engineers (USACE)).

Zebra mussels thrive in northern United States (U.S.) waters where water temperatures usually do not exceed 27 to $28^{\circ} \mathrm{C}$ (McMahon 1996). Aldridge, Payne, and Miller (1995) found high survival of zebra mussels at temperatures up to $32{ }^{\circ} \mathrm{C}$ in laboratory experiments. Allen, Thompson, and Ramcharan (1999) inferred that zebra mussel reproduction and survival would likely be adversely affected by the higher water temperatures present in most southern U.S. river systems. However, southern zebra mussel populations are firmly established despite initial predictions that summertime temperatures would preclude survival (Allen, Thompson, and Ramcharan 1999).

Another factor inhibiting zebra mussel expansion in southern waters may be predation by native fishes. Eggleton (2001) reported extensive (up to 26 percent of annual food consumption) use of zebra mussels by blue catfish Ictalurus furcatus in the main channel of the lower Mississippi River. Other regional reports indicate blue catfish and freshwater drum Aplodinotus grunniens in the Arkansas River, Arkansas (Magoulick and Lewis 2002); common carp Cyprinus carpio, other catfishes Ictalurus spp., and freshwater drum in the Cumberland River, Tennessee (Personal Communication, D. Hubbs, Tennessee Wildlife Resources Agency); and blue catfish, river carpsucker Carpiodes carpio, and smallmouth buffalo Ictiobus bubalus in the Ohio River (Thorp, Delong, and 
Casper 1998) also consume zebra mussels. Similar reports also exist from northern U.S. waters (e.g., French and Bur 1993; Tucker et al. 1996; French 1997; Marsden 1997; Morrison, Lynch, and Dabrowski 1997), principally with common carp and freshwater drum. Molloy et al. (1997) reported that up to 38 species of fish eat zebra mussels, though some species may be less adept because of gape limitations (e.g., French and Love 1995). However, they added that the few studies conducted suggest that fish predation does not significantly affect zebra mussel populations.

There are several possible reasons for lack of predatory control in northern U.S. waters. Physical conditions in many northern rivers and lakes mimic those in Eurasia, the native range of zebra mussels (Mackie and Schloesser 1996), and are conducive to their survival and proliferation. Many northern U.S. waters also have lower population densities of large-bodied omnivorous fishes (e.g., catostomids, catfishes, and freshwater drum) that could consume significant amounts of zebra mussels. This attribute, coupled with cooler water temperatures and lower bioenergetic demands of fishes (e.g., growth and metabolism) in most northern waters, suggests that fishes will consume less food. Thus, fish communities in many northern U.S. rivers and lakes may have less potential to impact zebra mussels. On the other hand, southern waters are generally warmer and often have greater standing crops of potential mussel predators (molluscivores) that include ictalurid catfishes, common carp, catostomid suckers, and freshwater drum. Growing seasons are longer in southern systems and allow resident fishes to exhibit high growth rates and attain large sizes. Thus, fishes in southern U.S. waters may have a competitive edge in controlling or restricting zebra mussels not possible in northern systems

The regulation or control of zebra mussels and other exotic molluscs by fishes through predation has not been widely assessed. French and Bur (1993) provided a review on the potential of several North American fishes to utilize zebra mussels based on the mouthpart morphology. Thorp, Delong, and Casper (1998) conducted a series of enclosure-exclosure experiments in the Upper Mississippi and Ohio rivers. They found fishes had a greater impact when zebra mussels occurred at low densities, but fish predation was still insufficient to impact mussels. Conversely, Robinson and Wellborn (1988) concluded that fishes in a Texas reservoir had great capacity to impact the invading Asiatic clam Corbicula fluminea, exhibiting as much as a 29-fold effect on clam abundance in cages where they had access. Thus, the few field studies conducted suggest the ability of fishes to impact exotic mussels may vary among systems and be related to latitude.

Enclosure-exclosure experiments provide insight into predatory mechanisms of many animals. However, the field of bioenergetics offers another approach to assess the potential for fishes to impact prey populations (e.g., Stewart, Kitchell, and Crowder 1981). Simple bioenergetic techniques, termed food consumption models, estimate the daily food consumption (ration) rate of fishes as a function of the amount of food observed in the stomach, gastric evacuation rate, and water temperature (e.g., Eggers 1977; Elliott and Persson 1978; Boisclair and Leggett 1988). Other approaches estimate population-level food consumption as a function of fish production rates, gross conversion efficiencies, or productionbiomass ratios (e.g., Eck and Wells 1983; Roell and Orth 1993). These 
approaches are termed production- or biomass-based models. More elaborate techniques, termed mass-balance models, relate the feeding and growth rates of fishes through construction of energetic mass budgets that balance energy acquisition (i.e., food consumption) with energy expenditures (i.e., metabolism, growth) and losses (i.e., waste) (Tytler and Calow 1985). Recent models developed for this purpose (e.g., the 'Wisconsin model' of Kitchell, Stewart, and Weininger 1977) use a series of sophisticated species-specific mass-balance algorithms applied to individual fishes and extrapolated to whole populations (e.g., Kitchell, Stewart, and Weininger 1977; Lyons and Magnuson 1987; Raborn 2000). The mass-balance approach has become the most common in North American fisheries research (Ney 1993), but it is restricted to species for which physiological parameters required by the model have been estimated. Parameters available (up to 30 per species) are almost exclusively limited to fishes common to the Great Lakes region (Hanson et al. 1997). However, all three types of bioenergetic models could be used to estimate potential impacts to zebra mussel populations across a latitudinal gradient.

This study uses a bioenergetic-based approach to investigate latitudinal effects on food consumption by fishes. We hypothesize that these latitudinal relationships coupled with regional differences in fish faunas and biomasses may be used to infer the relative potential for fishes to impact zebra mussels. Because physiological data needed to parameterize a mass-balance model were largely unavailable, our evaluation focused on the food consumption and a biomassbased models.

Our first objective was to simulate the annual food consumption of selected fishes in eight representative U.S. river and lake systems infested with zebra mussels. Daily food consumption was estimated on an individual-fish basis using a conventional food consumption model that integrated a generalized gastric evacuation model and average daily water temperature. This modeling yielded species-specific estimates of daily food consumption for each day of a typical year, which could then be summed to determine annual food consumption. The second objective involved simulating population-level consumption based on biomass for the same species in each system. A multivariate spatial analysis of fish communities across geographical regions was also conducted to augment biomass analyses. To accomplish each objective, we had to: (a) parameterize representative models for each species and system by review of pertinent literature; (b) compare predicted food consumption among species and across systems that represented different latitudes/longitudes and thermal regimes; and (c) use sensitivity analyses to assess the robustness of predictions and the relative importance of different model parameters. This overall approach differs from previous studies (e.g., Robinson and Wellborn 1988 and Thorp, Delong, and Casper 1998) but may be useful to resource managers involved with forecasting future zebra mussel impacts on aquatic ecosystems. 


\section{Methods and Materials}

\section{Study Areas}

We selected eight U.S. river and lake systems that were infested with zebra mussels for which adequate thermal data existed. Selected study systems were located along a 13-degree latitudinal gradient and a 12-degree longitudinal gradient from Louisiana north to Minnesota and east to Lake Erie (Figure 1). These systems included northern Lake Michigan, Upper Mississippi River (UMR) Pools 4, 13, and 26; Fox River; eastern Lake Erie; the upper Ohio River; and the Lower Mississippi River (LMR) (Table 1).

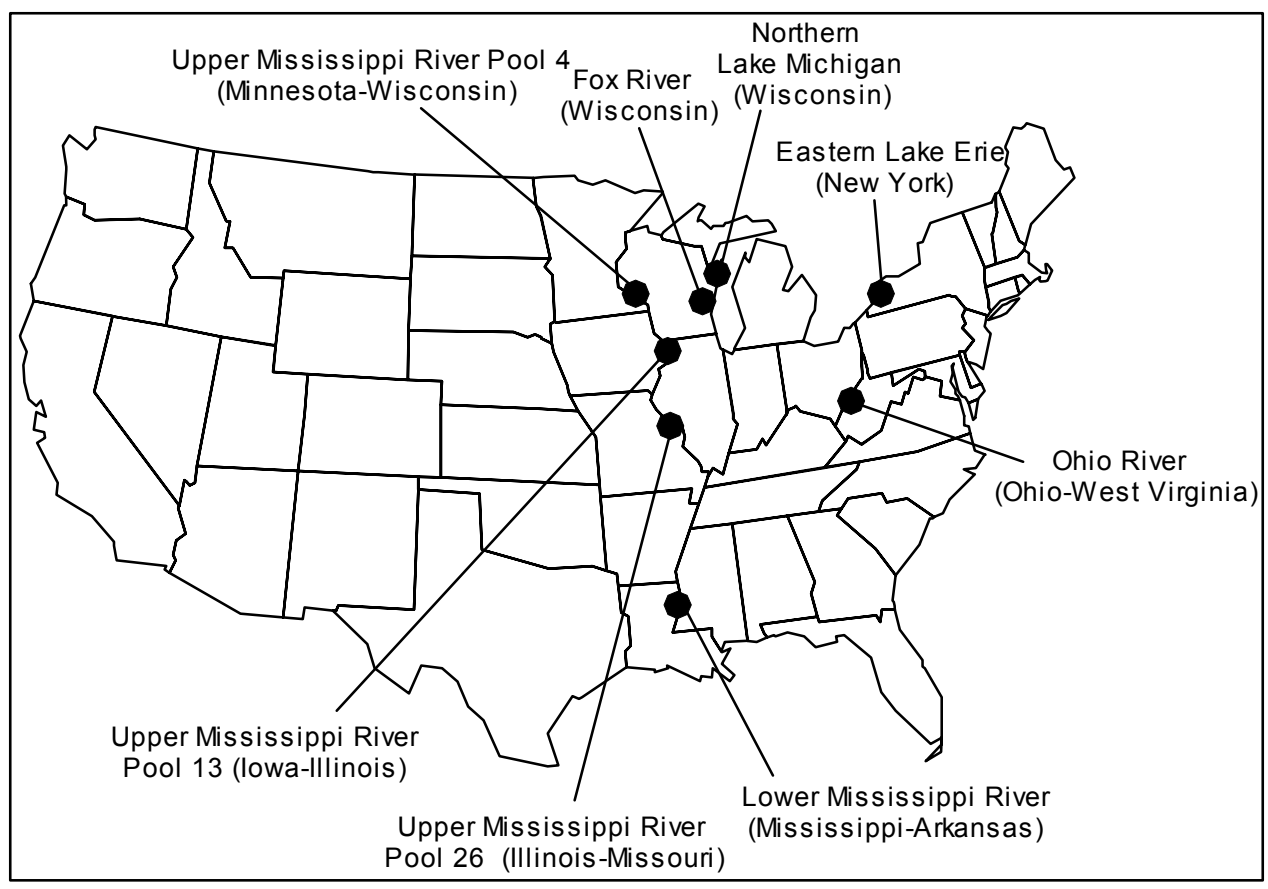

Figure 1. Geographic location of the eight study areas used for food consumption modeling simulations 


\begin{tabular}{|c|c|c|c|}
\hline \multicolumn{4}{|c|}{$\begin{array}{l}\text { Table } 1 \\
\text { River and Lake Systems Selected for Food Consumption Modeling } \\
\text { Simulations }\end{array}$} \\
\hline System & Location & Latitude $\left({ }^{\circ} \mathrm{N}\right)$ & Longitude ( $\left.{ }^{\circ} \mathrm{W}\right)$ \\
\hline Lower Mississippi River & " Mississippi-Arkansas & $\begin{array}{l}32.3089 \\
\end{array}$ & 90.908 \\
\hline Upper Miss River Pool 26 & Illinois-Missouri & 38.9276 & 90.2803 \\
\hline Ohio River & Ohio-West Virginia & 39.1072 & 81.7429 \\
\hline Upper Miss River Pool 13 & Illinois-lowa & 41.9594 & 90.1565 \\
\hline Lake Erie & New York & 42.8613 & 78.9215 \\
\hline Fox River & Wisconsin & 44.3075 & 88.2185 \\
\hline Upper Miss River Pool 4 & Minnesota-Wisconsin & 44.4202 & 92.1183 \\
\hline Lake Michigan & Wisconsin & 45.3300 & 86.4200 \\
\hline
\end{tabular}

\section{Selected Fish Species}

Molloy et al. (1997) reported up to 38 species of fish consume attached (nonveliger or adult) zebra mussels. However, geographic variation suggested that our best candidates were large, abundant, and geographically widespread omnivorous species. Given these criteria, we judged the best candidates included: common carp, freshwater drum, channel catfish Ictalurus punctatus, blue catfish, lake sturgeon Acipenser fulvescens, spotted sucker Minytrema melanops, river carpsucker, buffalofishes Ictiobus spp., and redhorse suckers Moxostoma spp.. Because the latter two groups contained several species of similar morphology and overlapping distributions, collective grouping at the genus level was done in lieu of assessing each species individually. Eight of the nine species/genera were modeled using the biomass-based approach-lake sturgeon were excluded because too few biomass estimates were available for meaningful analysis.

\section{Food Consumption Model}

Using the food consumption approach, only common carp, freshwater drum, channel catfish, and lake sturgeon were modeled because of the extensive time required to run individual simulations. Given that only the growth variable differs among species in the food consumption model, we did not believe running the full complement of simulations (i.e., all systems, ages, and growth scenarios) for all species would be worthwhile.

a. Approximation of growth. Estimates of fish size and growth were needed to simulate annual food consumption. Modeling of daily food consumption incorporated estimates of stomach fullness expressed as a proportion of total weight. Because we needed generalized estimates of fish growth across a large geographic area, we used length-at-age data reported by Carlander $(1969,1977,1997)$. Data sets from diverse geographic areas were used in the development of generalized length-atage curves that were then converted to weight-at-age curves (Table 2) using weight-length relations reported in Carlander (1969, 1977, 1997). Mean weight-at-age curves were then used to depict generalized annual 
growth curves for each species. In addition, given that fish growth can be highly system-specific (DeVries and Frie 1996), fast-growth (mean weight-at-age +20 percent) and slow-growth (mean weight-at-age 20 percent) scenarios were also modeled to provide robustness.

Simulations were conducted for three age intervals for each species: ages 3 to 4,5 to 6 , and 7 to 8 .

\begin{tabular}{|c|c|c|c|c|c|}
\hline \multicolumn{6}{|c|}{$\begin{array}{l}\text { Table } 2 \\
\text { Generalized Weight-Length Regression Equations and Weight-At-Age Estimates Used } \\
\text { for Each Species in this Evaluation }\end{array}$} \\
\hline Species & $\begin{array}{l}\text { Generalized Weight- } \\
\text { Length Equations }\end{array}$ & $\begin{array}{l}\text { Estimated Weights } \\
\text { From Ages } 1-10\end{array}$ & $\begin{array}{l}\text { Weight } \\
\text { Interval } \\
\text { Age 3-4 } \\
\text { (wt. gain) }\end{array}$ & $\begin{array}{l}\text { Weight } \\
\text { Interval } \\
\text { Age 5-6 } \\
\text { (wt. gain) }\end{array}$ & $\begin{array}{l}\text { Weight } \\
\text { Interval } \\
\text { Age 7-8 } \\
\text { (wt. gain) }\end{array}$ \\
\hline $\begin{array}{l}\text { Common } \\
\text { carp }\end{array}$ & $-4.489+2.832 \log _{10}(T L)$ & $\begin{array}{l}62,311,722,1120,1501 \\
1918,2172,2624,3000 \\
3423\end{array}$ & $722-1120(398)$ & $\begin{array}{l}1501-1918 \\
(417)\end{array}$ & $\begin{array}{l}2172-2624 \\
(452)\end{array}$ \\
\hline $\begin{array}{l}\text { Freshwater } \\
\text { drum }\end{array}$ & $-5.419+3.204 \log _{10}(T L)$ & $\begin{array}{l}29,219,492,720,848 \\
1639,1803,2166,2575 \\
3035\end{array}$ & $492-720(268)$ & $848-1639(791)$ & $\begin{array}{l}1803-2366 \\
(563)\end{array}$ \\
\hline $\begin{array}{l}\text { Channel } \\
\text { catfish }\end{array}$ & $-5.508+3.290 \log _{10}(T L)$ & $\begin{array}{l}13,83,219,439,756, \\
1226,1653,2324,3904, \\
4780\end{array}$ & $219-439(220)$ & $756-1226(470)$ & $\begin{array}{l}1653-2324 \\
(671)\end{array}$ \\
\hline $\begin{array}{l}\text { Lake } \\
\text { sturgeon }\end{array}$ & $-3.482+2.837 \log _{10}(\mathrm{FL})$ & $\begin{array}{l}\text { 1816, 4709, 5511, 9096, } \\
\text { 16670, 19747, 21095, } \\
23737,28343,40489, \\
70609\end{array}$ & $\begin{array}{l}5511-9096 \\
(3585)\end{array}$ & $\begin{array}{l}16670-19747 \\
(3077)\end{array}$ & $\begin{array}{l}21095-23737 \\
(2642)\end{array}$ \\
\hline
\end{tabular}

b. Model parameterization. Our goal was to estimate, mean daily food consumption for each target species in each river or lake system. Each simulation encompassed a 365-day period beginning on July 1 (day 1) and ending on June 30 (day 365). Simulations were accomplished using a conventional food consumption model, a model for generalized estimates of fish gastric evacuation rate, and average daily water temperatures. The 365 estimates of mean daily ration were then summed to determine annual food consumption for a typical individual of each species (i.e., common carp, freshwater drum, channel catfish, and lake sturgeon) in each system.

Food consumption models estimate a daily (i.e., 24-hr) ration by integrating the observed amount of food in the stomach at a point in time with estimated instantaneous rate of gastric evacuation. It was assumed that fishes fed randomly throughout a 24-hr cycle. We used the Eggers food consumption model (Eggers 1977, 1979):

$$
C_{d}=24 \times S_{t} \times R
$$


where

$S_{t}=$ weight-specific amount of food in the fish stomach determined from stomach fullness (expressed as g wet-weight $\cong$ fish $^{-1}$ )

$R=$ instantaneous evacuation rate

$24=$ hours in a day.

Instantaneous rates of gastric evacuation were estimated as a function of water temperature and meal size using a generalized model developed for fishes (He and Wurtsbaugh 1993):

$$
R=0.049 e^{[(0.072 \times T)-(0.006 \times \log e(M S))]}
$$

where

$$
\begin{aligned}
\mathrm{T} & =\text { daily mean water temperature }\left({ }^{\circ} \mathrm{C}\right) \\
\mathrm{MS} & =\text { estimated meal size (g wet-weight). }
\end{aligned}
$$

Meal size was approximated based on a mean stomach fullness (i.e., weight of stomach contents / weight of the fish) of 1 percent of the fish total weight with a possible range of 0 to 4 . These ranges of stomach fullness were based on estimates provided in the literature for several species of small and large-bodied fishes (e.g., Armstrong and Brown 1983; DeMauro and Miranda 1990; Keast and Fox 1992; Driscoll and Miranda 1999). Stomach fullness means and ranges for two of the target species collected from the lower Mississippi River (almost 2,000 fishes collected over 2 years) were also considered (Eggleton, M. A. unpublished data). The generalized evacuation model of He and Wurtsbaugh (1993) was based on 121 published gastric evacuation estimates that included 22 species of freshwater fishes (weights 10 to 1,300 g wet-weight) at water temperatures ranging from 2 to $27^{\circ} \mathrm{C}$; however, none of our target species were included in its development. Temperature ranges for some of our study systems also approximated the upper and lower limits of temperatures used by He and Wurtsbaugh in their model. Thus, to add robustness to our daily food consumption predictions, we made 1,000 estimates of evacuation rate for each day of each simulation using random estimates of the model coefficients, and meal size. Random estimates of the evacuation model coefficients were selected within triangular constraints of the 90 percent confidence intervals for each coefficient (Miranda, Hargreaves, and Raborn 2001). Similar estimates of meal size were made using a mean of 1 percent and a range of 0 to 4 percent. Because daily water temperatures for each system were daily means from at least several years of data, estimates were believed reasonably precise and, therefore, fixed for each day during simulations.

\section{Biomass-based Model}

We estimated population-level annual food consumption for eight fish species in each river and lake system as a function of production rates (derived from biomass data), gross conversion efficiencies, and production-biomass ratios. 
Biomass data were obtained from a data set containing estimates for all fish species from 396 U.S. reservoirs. Thirty-two additional biomass estimates were obtained for the Upper and Lower Mississippi Rivers. Reservoir estimates were compiled primarily from state fish and game agencies from Florida north to Maryland and the Ohio River and west to Kansas and Texas. River biomass estimates were compiled from Federal Government Agencies, namely the U.S. Army Corps of Engineers for the Lower Mississippi River (Cobb et al. 1984) and the U.S. Fish and Wildlife Service - Upper Mississippi River Conservation Commission for the Upper Mississippi River (Pitlo 1987).

a. Model parameterization. Using these data, we constructed least-squares linear regression models of $\log _{e}$ fish biomass versus latitude, longitude, and latitude-longitude interaction for each target species. The predicted biomass of each study system was used to estimate the expected average biomass such that:

expected $\log _{e}$ (fish biomass) $=\mathrm{a}+$

b(latitude) $+c($ longitude) $+d($ interaction)

where a, b, c, and d were estimated parameters.

The product of the expected biomass for a particular system and the range of expected production-biomass (P-B) ratios for warmwater fishes from the literature (mean 2.5, range 0.5 to 4.5 (Neves 1981)) yielded the estimated annual production for each species in that system. Thus,

$$
P=B \cdot P-B
$$

where

$$
\begin{aligned}
B & =\text { predicted biomass in } \mathrm{kg} \cong \mathrm{ha}^{-1} \\
P-B & =\text { production-biomass ratio }
\end{aligned}
$$

Dividing the predicted annual production by the expected range of gross conversion efficiencies (GCE) for fishes (mean 0.1, range 0.01 to 0.2; Brett and Groves 1979) yielded the estimated annual food consumption for each species in a particular system. Thus,

$$
C_{t}=P /(G C E)
$$

where

$$
\begin{aligned}
C_{t} & =\text { population-level annual food consumption in } \mathrm{kg} \cong \mathrm{ha}^{-1} \cong \mathrm{yr}^{-1} \\
\mathrm{P} & =\text { annual fish production in } \mathrm{kg} \cong \mathrm{ha}^{-1} \\
\mathrm{GCE} & =\text { growth/consumption (gross conversion efficiency) }
\end{aligned}
$$


Estimates of P-B ratio and GCE were not available for the systems or species of interest. However, individual estimates and generalized ranges for other species and systems were available in the primary literature. Thus, to assure robustness to our predictions, 5,000 random estimates of predicted biomass were generated for each species and system within triangular constraints of the 90 -percent confidence intervals of the $\log _{e}$ (biomass)-latitude/longitude regression models. In addition, 5,000 random estimates of P-B ratio were generated using a mean of 2.5, a minimum of 0.5 , and a maximum of 4.5; similarly, 5,000 random estimates of GCE were generated using a minimum of 1 percent, mean of 10 percent, and a maximum of 20 percent. The product of each set of biomass estimates, P-B ratios, and GCE values yielded 5,000 estimates of populationlevel food consumption for each species and system. Plotting the frequency of these expected values for each river or lake system simulated a distribution of expected or potential consumption values for each species in each system from which means and standard errors could be estimated. Given the randomization process, this approach provided a reasonably robust yet conservative estimation of potential annual food consumption for each target species.

b. Spatial analysis of fish biomass. To complement the biomass-based modeling, we used correspondence analysis (CA) ( Legendre and Legendre 1998) to examine regional variation in fish community biomass (standing crop). CA is an indirect gradient analysis useful in analyzing species $\mathrm{H}$ site data matrices. Eigenvalues and axis loadings were calculated with PC-ORD Version 4 (McCune and Mefford 1999). Although CA has been criticized for creating the spurious "arch" effect on the second and subsequent ordination axes (Hill and Gauch 1980), a similar analysis correcting for this arch (detrended CA) yielded patterns very similar to $\mathrm{CA}$. Because rare species can potentially be problematic, species that occurred only once in the data set were omitted from the analysis; lumped taxa (e.g., minnows) were also omitted. Species biomass estimates were square-root transformed to reduce the dominating effect of the most common species (M.W. Palmer, Ordination Methods for Ecologists website, Oklahoma State University).

\section{Model Sensitivity Analyses}

Sensitivity analyses were used to assess reliability of predictions and the relative importance of model parameters. Variability of model output was simulated with probabilistic (Monte Carlo) assessment methodology wherein values of model parameters were randomly selected from statistical distributions. Sensitivity analyses of the food consumption model were generated by altering the five primary model parameters (water temperature, stomach fullness, and the intercept and slope coefficients from the gastric evacuation model) by $\pm 5,10$, 15, 20, and 30 percent. Each parameter was varied individually, with the others held to their original values. Random values of each adjusted parameter were drawn from within triangular constraints of each as described earlier. Similarly, sensitivity of the biomass-based model involved varying the four primary parameters (intercept and slope coefficient of the biomass-latitude/longitude regression, P-B ratio, and GCE) by \pm 5, 10, 15, 20, and 30 percent. Each 
parameter was varied individually, with the others constant. Following each simulation, the resulting percent change in annual consumption was then determined and used as an index of the model's sensitivity to that parameter. 


\section{Results}

\section{Food Consumption Model}

Thermal differences affecting rates of food consumption existed among study areas (Figure 2). In northern Lake Michigan, water temperatures did not exceed $20{ }^{\circ} \mathrm{C}$, and were $>15{ }^{\circ} \mathrm{C}$ only during a 2-month period from mid-July through mid-September. The growing season for warmwater fishes (period with temperatures $\geq 15^{\circ} \mathrm{C}$ ) was estimated to be about 75 days.year ${ }^{-1}$ (21 percent of the year) in northern Lake Michigan (Table 3). At other end of the spectrum in the LMR, water temperatures exceeded $20^{\circ} \mathrm{C}$ during 41 percent of the year; overall in the LMR, the average growing season was estimated to be 200 days $\cdot$ year $^{-1}$. The rank order of warmest to coolest systems did not strictly correspond with latitudinal gradient. The Ohio River, which flows approximately east to west and drains the Mid-Atlantic Highlands region, was on average warmer than the UMR Pool 26, despite greater latitude. The Fox River and UMR Pool 4 were also warmer than Lake Erie. In spite of its latitude, Lake Erie was the second coolest system with the second shortest growing season-only 34 percent of the year (Table 3). Lake Erie is the downstream outlet for all of the upper Great Lakes (i.e., Superior, Michigan, and Huron), which are all relatively colder systems supporting predominately coolwater (e.g., esocids and percids) and coldwater (e.g., salmonid) fisheries (Jude and Leach 1999).

Latitudinal variations in annual food consumption paralleled water temperature. With ages 3 to 4 common carp, annual consumption in the LMR (warmest system) exceeded that in northern Lake Michigan (coolest system) by 117 percent in the average-growth simulation (Figure 3). Similarly, proportional differences were 112 percent during the slow-growth simulation and 115 percent during the fast-growth simulation (Figure 3 ). Comparable patterns were observed with ages 5 to 6 and ages 7 to 8 cohorts. Ranked from greatest to least, annual food consumption ordered as follows: the LMR, Ohio River, UMR Pool 26, UMR Pool 13, UMR Pool 4, Fox River, Lake Erie, and northern Lake Michigan. This ranking of annual food consumption followed exactly as did mean annual water temperatures and nearly corresponded with estimated length of growing seasons (Table 3). Identical patterns were observed from simulations with the other target species (Figures 4 through 6). 


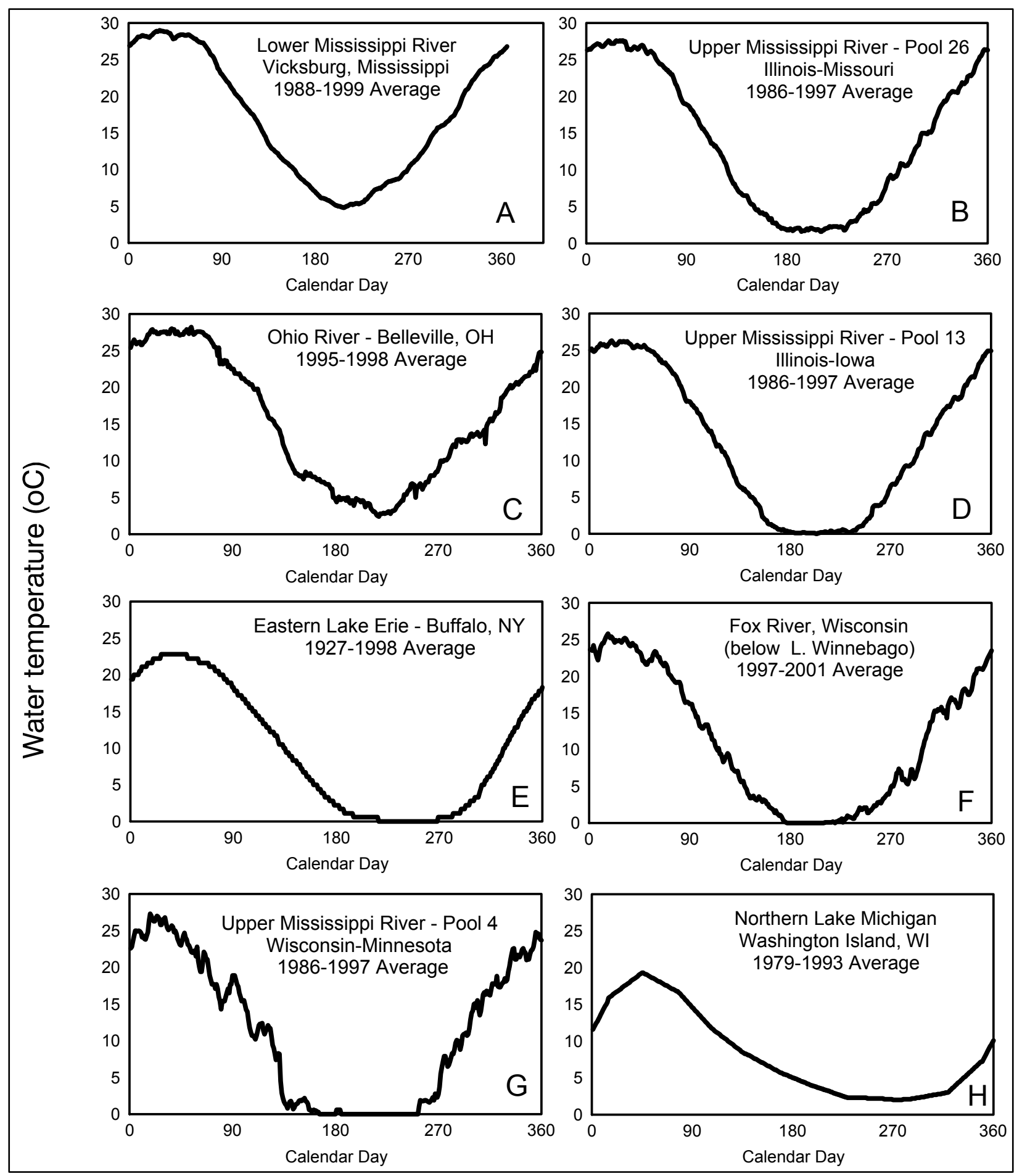

Figure 2. Annual thermographs for several U.S. river and lake systems where zebra mussels are present. River and lake systems are arranged A-H by increasing latitude. Data provided by the U.S. Army Corps of Engineers and U.S. Geological Survey 


\begin{tabular}{|c|c|c|c|c|}
\hline \multicolumn{5}{|c|}{$\begin{array}{l}\text { Table } 3 \\
\text { Thermal Characteristics of the Eight River and Lakes Systems } \\
\text { Used for Food Consumption Simulations. Systems Ordered by } \\
\text { Latitude }\end{array}$} \\
\hline System & $\begin{array}{l}\text { Mean Annual Water } \\
\text { Temperature and Range } \\
\left({ }^{\circ} \mathrm{C}\right)\end{array}$ & $\begin{array}{l}\text { Length of } \\
\text { Growing } \\
\text { Season }^{1}\end{array}$ & $\begin{array}{l}\text { \% Days } \\
\geq 15^{\circ} \mathrm{C}\end{array}$ & $\begin{array}{l}\% \text { Days } \\
\geq 20^{\circ} \mathrm{C}\end{array}$ \\
\hline $\begin{array}{l}\text { Lower } \\
\text { Mississippi River }\end{array}$ & $16.9(4.8-29.0)$ & 200 & 55 & 41 \\
\hline $\begin{array}{l}\text { Upper Miss River } \\
\text { Pool } 26\end{array}$ & $13.9(1.6-27.6)$ & 167 & 46 & 34 \\
\hline Ohio River & $15.4(2.4-28.4)$ & 179 & 49 & 38 \\
\hline $\begin{array}{l}\text { Upper Miss River } \\
\text { Pool } 13\end{array}$ & $12.4(0.0-26.3)$ & 156 & 43 & 30 \\
\hline Lake Erie & $10.0(0.0-22.8)$ & 125 & 34 & 19 \\
\hline Fox River & $11.2(-0.3-25.8)$ & 149 & 41 & 26 \\
\hline $\begin{array}{l}\text { Upper Miss River } \\
\text { Pool } 4\end{array}$ & $11.4(0.0-27.3)$ & 160 & 44 & 28 \\
\hline Lake Michigan & $8.2(2.0-19.3)$ & 75 & 21 & 0 \\
\hline Means & & 151 & 42 & 27 \\
\hline
\end{tabular}

Size differences among species directly contributed to observed differences in food consumption. For instance, consumption by ages 3 to 4 lake sturgeon (greatest annual consumption) exceeded that of ages 3 to 4 channel catfish (least annual consumption) by 2,600 percent (Table 4). Similar trends in sturgeon consumption were observed over common carp (780 percent) and freshwater drum (1,260 percent). Consumption by common carp exceeded that of freshwater drum and channel catfish by 55 and 207 percent, respectively (Table 4). Freshwater drum consumption exceeded that of channel catfish by 99 percent (Table 4). Lake sturgeon are large, long-lived species (Billard and Lecointre 2001) and mean size between ages 3 and 4 was estimated to be $7.3 \mathrm{~kg}$ (Carlander 1969). Thus, using 1-percent stomach fullness as a guideline in the modeling, approximately $507 \mathrm{~g}$ of food consumption was estimated for each day in the LMR. These results alone suggest that lake sturgeon individually may have the greatest potential to impact zebra mussels in the aquatic systems modeled, because of their fast growth (relative to the other target species) and great size. However, other factors such as the species' distribution, population density, size structure, and local abiotic conditions will dictate the overall potential of a specific population to impact zebra mussels in a particular system. 


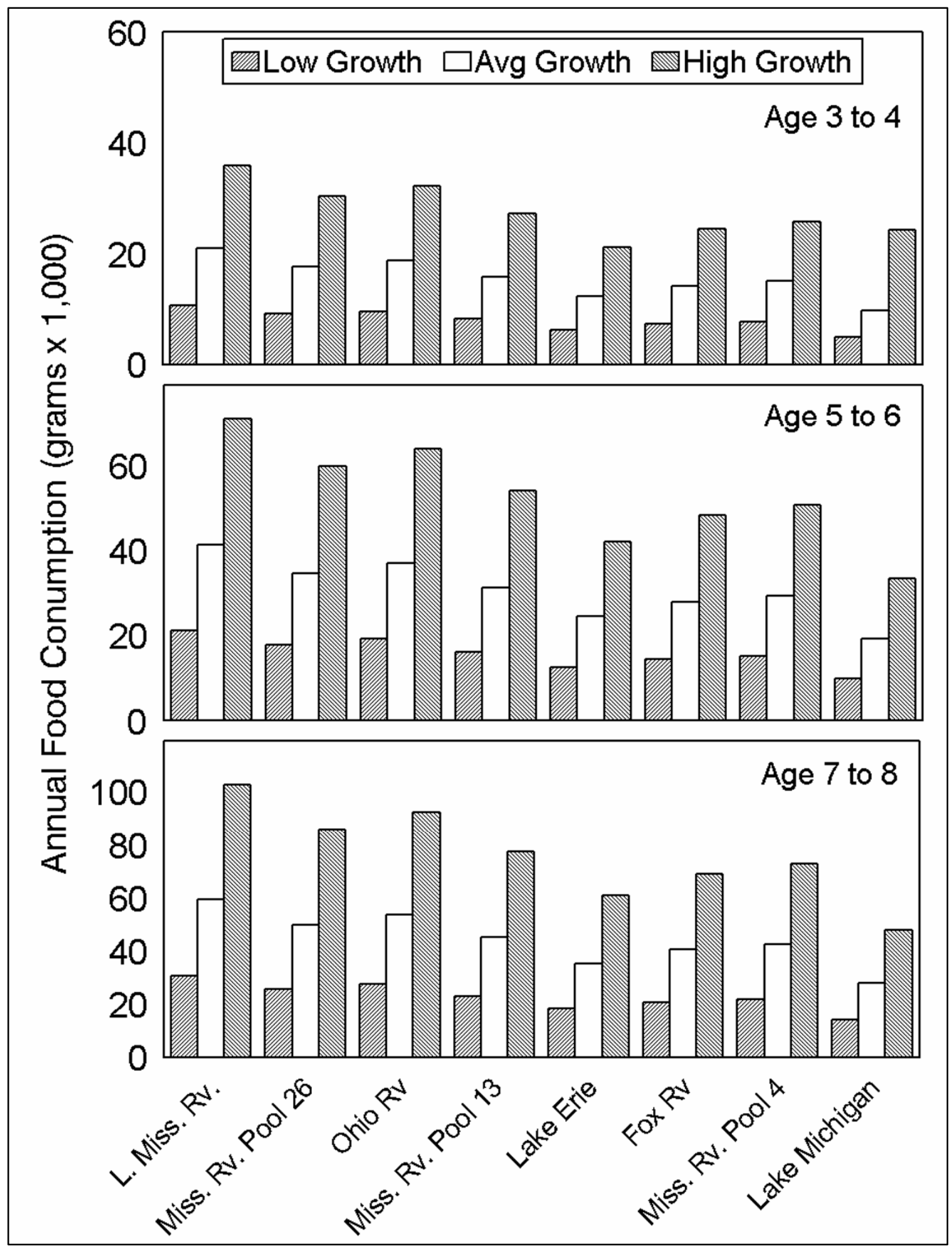

Figure 3. Simulated annual food consumption of common carp from eight U.S. river and lake systems during a year of average thermal conditions. Simulation determined from ages 3 to 4 , ages 5 to 6 , and ages 7 to 8 . River and lake systems arranged by latitude 


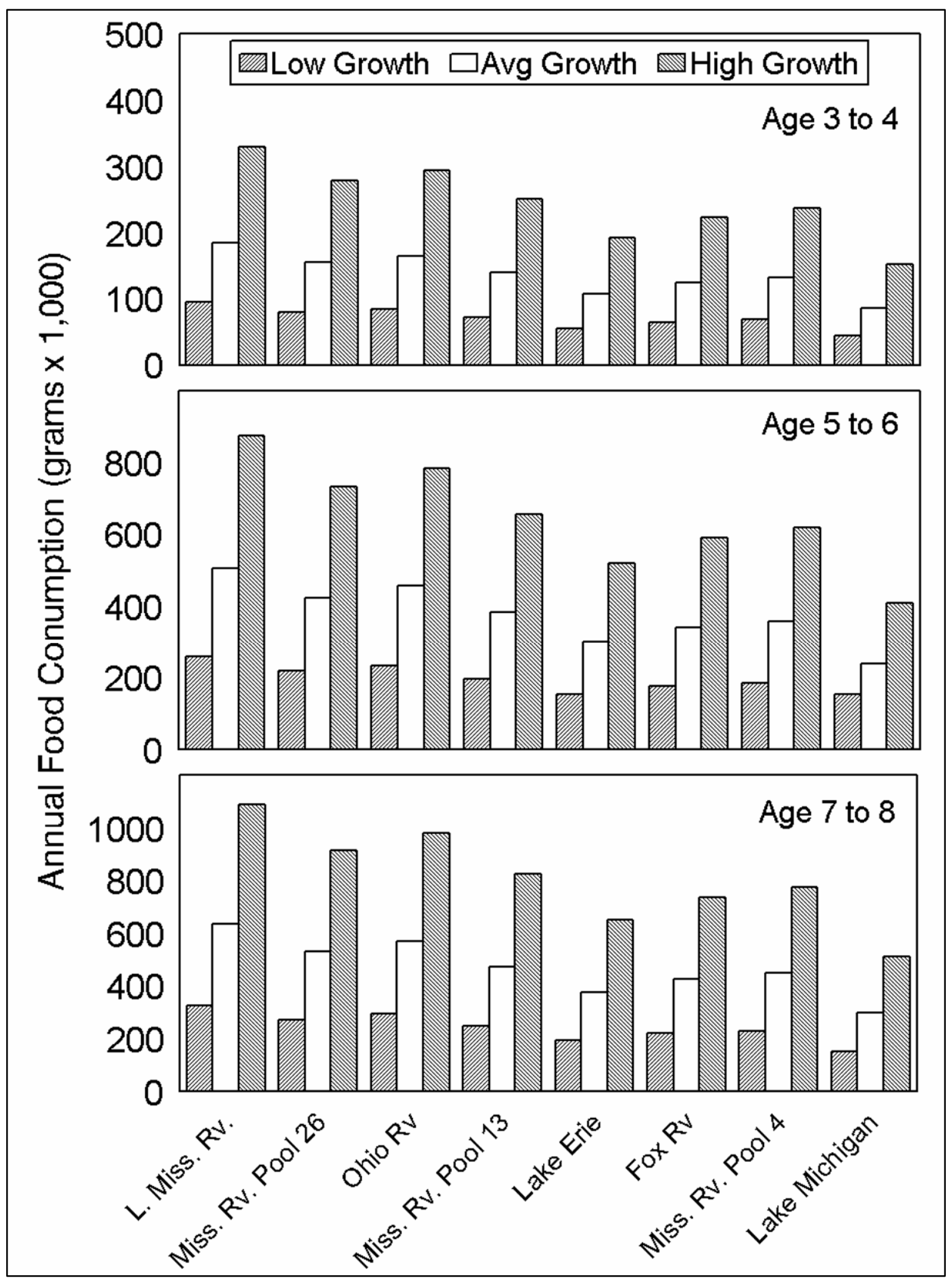

Figure 4. Simulated annual food consumption of lake sturgeon from eight U.S. river and lake systems during a year of average thermal conditions. Simulation determined from ages 3 to 4 , ages 5 to 6 , and ages 7 to 8 . River and lake systems arranged by latitude 


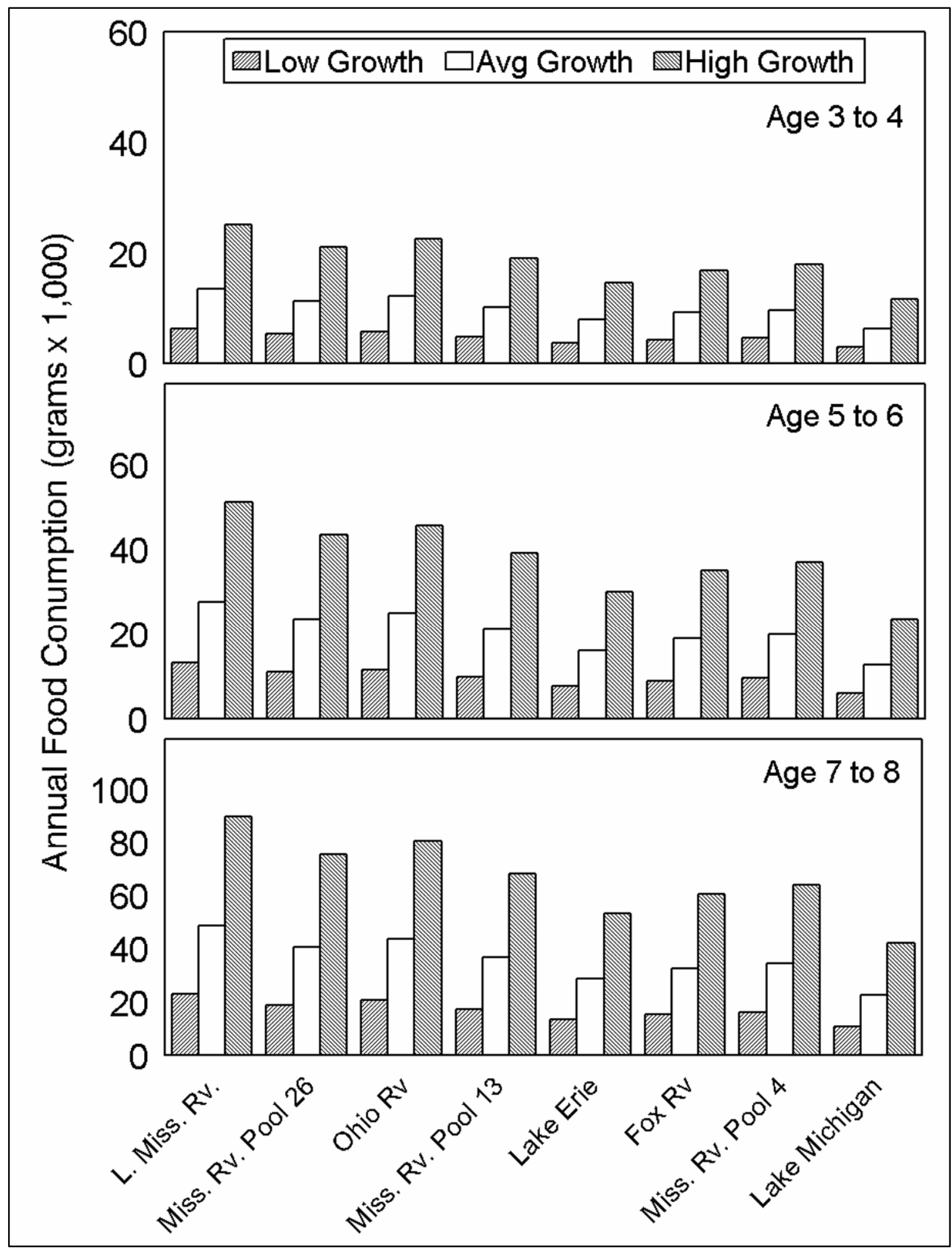

Figure 5. Simulated annual food consumption of freshwater drum from eight U.S. river and lake systems during a year of average thermal conditions. Simulation determined from ages 3 to 4 , ages 5 to 6 , and ages 7 to 8 . River and lake systems arranged by latitude 


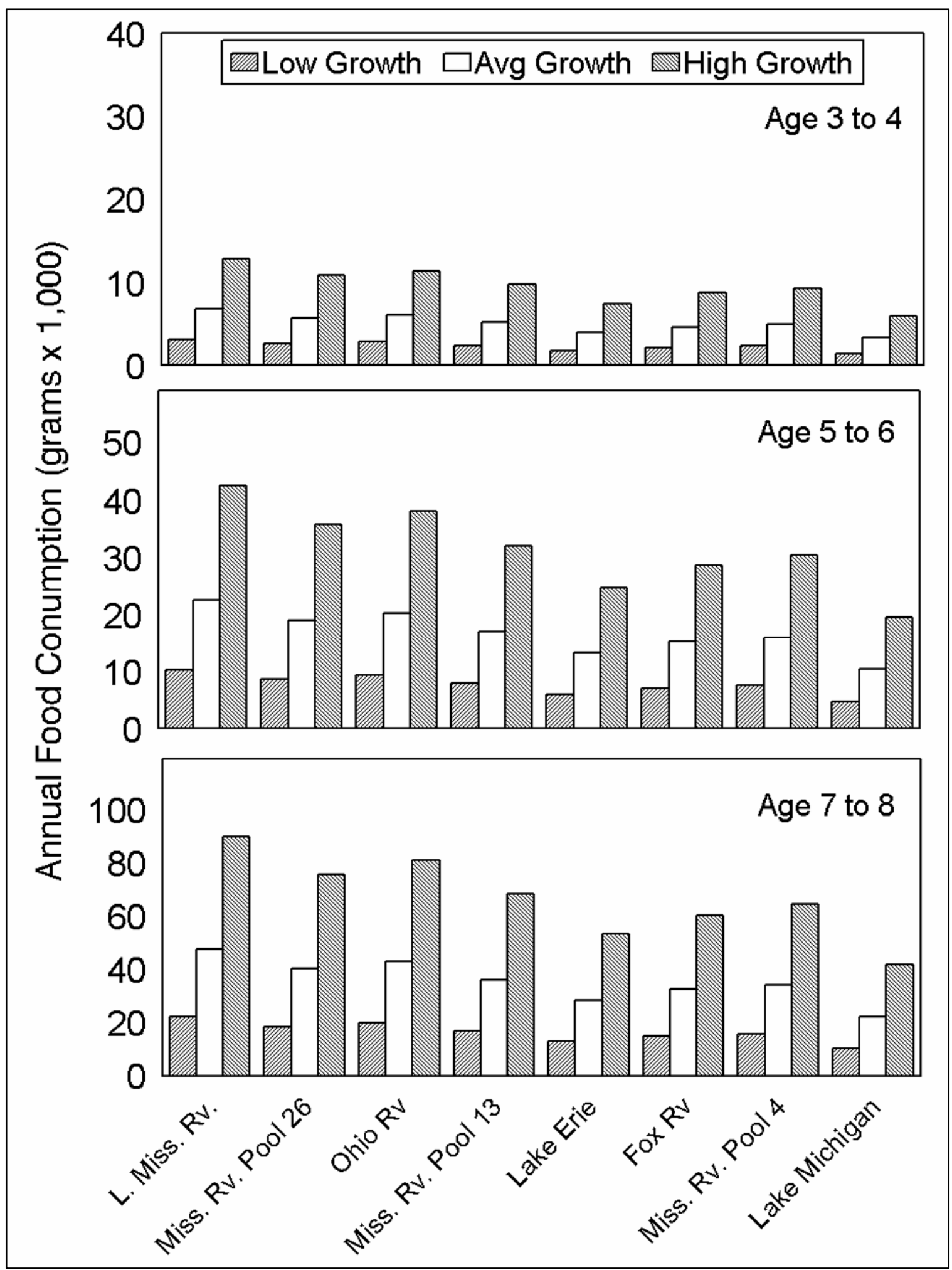

Figure 6. Simulated annual food consumption of channel catfish from eight U.S. river and lake systems during a year of average thermal conditions. Simulation determined from ages 3 to 4 , ages 5 to 6 , and ages 7 to 8 . River and lake systems arranged by latitude 


\section{Table 4 \\ Mean Proportional (\%) Increases ${ }^{1}$ in Annual Consumption by Target Species Averaged Across Eight River and Lake Systems. Three values in each cell represent means for ages 3 to 4,5 to 6 , and 7 to 8 , respectively}

\begin{tabular}{||l|l|l|l|}
\hline \hline Species & Lake Sturgeon & Common Carp & Freshwater Drum \\
\hline \hline Common carp & $780,1171,951$ & & \\
\hline Freshwater drum & $1260,1783,1184$ & $54.7,48.3,22.2$ & \\
\hline Channel catfish & $2600,2232,1206$ & $207,83.5,24.3$ & $98.6,23.8,1.7$ \\
\hline
\end{tabular}

${ }^{1}$ Percentage increases expressed for species listed in columns 2 through 4 relative to species listed in rows 1 through 3 . For example, lake sturgeon consumption exceeded common carp consumption by 780 percent, 1,171 percent, and 951 percent for ages 3 to 4,5 to 6 , and 7 to 8 , respectively.

Interspecific differences in annual food consumption varied among cohorts. Annual consumption by lake sturgeon exceeded all other species, exceeding channel catfish by 2,600 percent for ages 3 to 4, 2,232 percent for ages 5 to 6 , and 1,206 percent for ages 7 to 8 (Table 4). However, proportional differences between the other species were much less because of more similar sizes of the cohorts. Consumption by common carp exceeded that of freshwater drum by 55 percent for ages 3 to 4, 48 percent for ages 5 to 6 , and 22 percent for ages 7 to 8 (Table 4). Similarly, carp consumption exceeded channel catfish by 207 percent for ages 3 to 4, 84 percent for ages 5 to 6 , and 24 percent for ages 7 to 8 (Table 4). Freshwater drum consumption exceeded that of channel catfish by 99 percent for ages 3 to 4, 24 percent for ages 5 to 6 , and 2 percent for ages 7 to 8 cohorts (Table 4). Excluding lake sturgeon, differences in annual food consumption among species became less as size increased. In other words, as fish size increased, different species exhibited more similar potentials to impact zebra mussels. This observation underscores that fish population size/age structure may be an important determinant in a species' ability to impact zebra mussels by predation.

\section{Biomass-based Food Consumption}

The data set used to generate biomass-based food consumption contained few estimates from north of the Ohio River, Missouri, and Kansas and many from the central and southern United States. Thus, biomass-based results need interpretation within that context. Total fish biomass ranged from 14 to $1,771 \mathrm{~kg} \cdot \mathrm{ha}^{-1}$ and averaged $333 \mathrm{~kg} \cdot \mathrm{ha}^{-1}( \pm 13.3)$ for all systems in the data set. Multiple linear regression modeling biomass as a function of latitude, longitude, and latitude-longitude interaction were usually significant, but few models had significant terms. Some significant latitudinal and longitudinal relationships were detected with total fish biomass and biomass of spotted sucker, river carpsucker, and redhorses. Total fish biomass exhibited a slight inverse relationship with latitude $(\mathrm{P}=0.024)$ and direct relationship with longitude $(P=0.047)$ (Figure 7), suggesting greater total fish biomasses in central U.S. systems (e.g., Missouri, Kansas, and Illinois). Similarly, biomasses of spotted sucker $(\mathrm{P}=0.035$ - 0.045) and river carpsucker $(\mathrm{P}=0.034-0.05)$ exhibited direct relationships with latitude and longitude, which also suggested greater 
biomasses of those species in central U.S. systems (Figures 8 and 9). Redhorses ( $\mathrm{P}<0.0001)$ exhibited significant relationships with latitude and longitude ( $\mathrm{P}<0.0001)$, but the relationship was direct for latitude and inverse for longitude (Figure 10). Results suggested greater biomasses of redhorses in the upper Ohio River drainage and Atlantic seaboard states (e.g., West Virginia, Virginia, and North Carolina) and lower biomasses in southwestern systems (e.g., Texas, Oklahoma, and Louisiana). In contrast, despite that overall models were highly significant, biomasses of common carp $(\mathrm{P}=0.47-0.54)$, freshwater drum $(\mathrm{P}=0.43$ - 0.61), and channel catfish $(\mathrm{P}=0.17-0.35)$ exhibited no significant relationships with either latitude or longitude (Figures 11 to13). Overall regression models were not significant for blue catfish $(\mathrm{P}=0.19)$ or buffalo fishes $(\mathrm{P}=0.88)$ (Figures 14 and15).

In general, regression models indicated that the biomass of several key species likely to consume zebra mussels (e.g., channel catfish, common carp, and freshwater drum) did not vary appreciably across latitudes (10 to $30 \mathrm{~kg} \cdot \mathrm{ha}^{-1}$ change), being similar in both southern and northern systems. Thus, these species' ability to impact zebra mussels via predation varied little with latitude (i.e., across systems). Latitudinal biomass increases of other species likely to consume zebra mussels (e.g., spotted sucker and redhorses) were detected. However, the rate of biomass increase versus latitude for these species was small, increasing on average from 2 to $4 \mathrm{~kg} \cdot \mathrm{ha}^{-1}$ in more southern latitudes to around 5 to $8 \mathrm{~kg} \cdot \mathrm{ha}^{-1}$ in more northern latitudes. Biomass increases detected with river carpsucker were more substantial, ranging from $5 \mathrm{~kg} \cdot \mathrm{ha}^{-1}$ in lower latitudes to around $20 \mathrm{~kg} \cdot \mathrm{ha}^{-1}$ in greater latitudes. Thus, we would expect their impact to be intermediate between common carp, freshwater drum, channel catfish, and spotted sucker-redhorse groups.

Predicted food consumption from biomass-latitude/longitude regression models provided mixed results. Models indicated that population-level food consumption decreased by 25 percent for channel catfish, 49 percent for freshwater drum, and 75 percent for blue catfish between the LMR and northern Lake Michigan, the most southern and northern systems modeled (Table 5). In contrast, consumption increased for common carp by 62 percent (Table 5) and spotted sucker by 27 percent over this same range of systems (Table 6). More drastic increases were observed with river carpsucker (901 percent) and redhorses (412 percent) (Table 6), but as before, predicted biomasses of these species were much lower overall. Overall, biomass-based models indicated that cumulative food consumption of the eight target species increased by 69 percent between the LMR and northern Lake Michigan, presumably the result of greater biomasses of some of these species in more northern systems. However, at the same time, cumulative food consumption of the entire fish community decreased by 21 percent in northern Lake Michigan compared to the LMR. Thus, in spite of the proportional increases exhibited by some species, the total food consumed by all fish species declined one-fifth with latitude. 


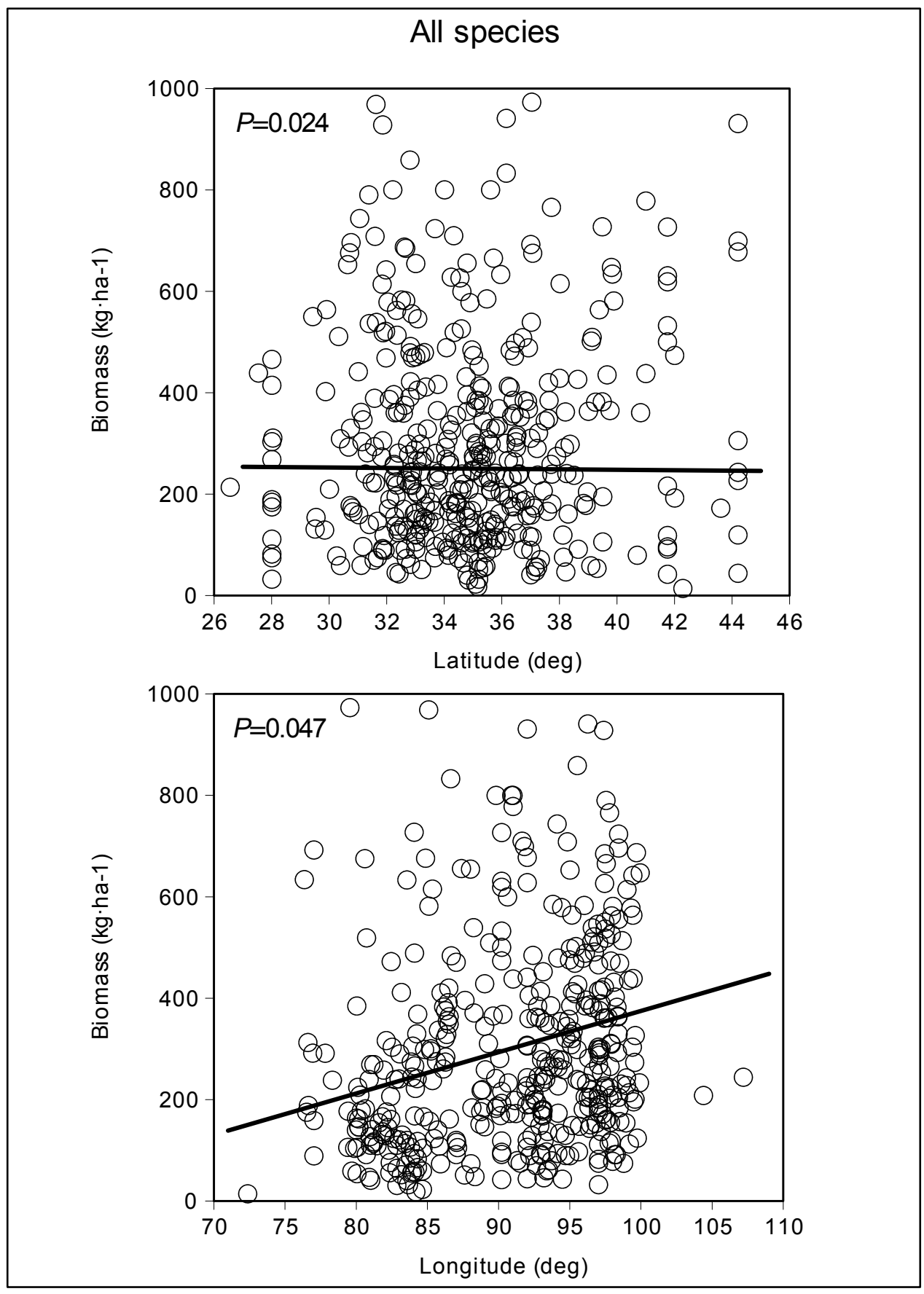

Figure 7. Linear regression analysis of total fish biomass vs. latitude and longitude for 428 reservoir and river systems in the United States. Systems are located from Texas east to Florida and north to the Ohio River, Missouri, and Kansas. P value represents significance level of the regression 


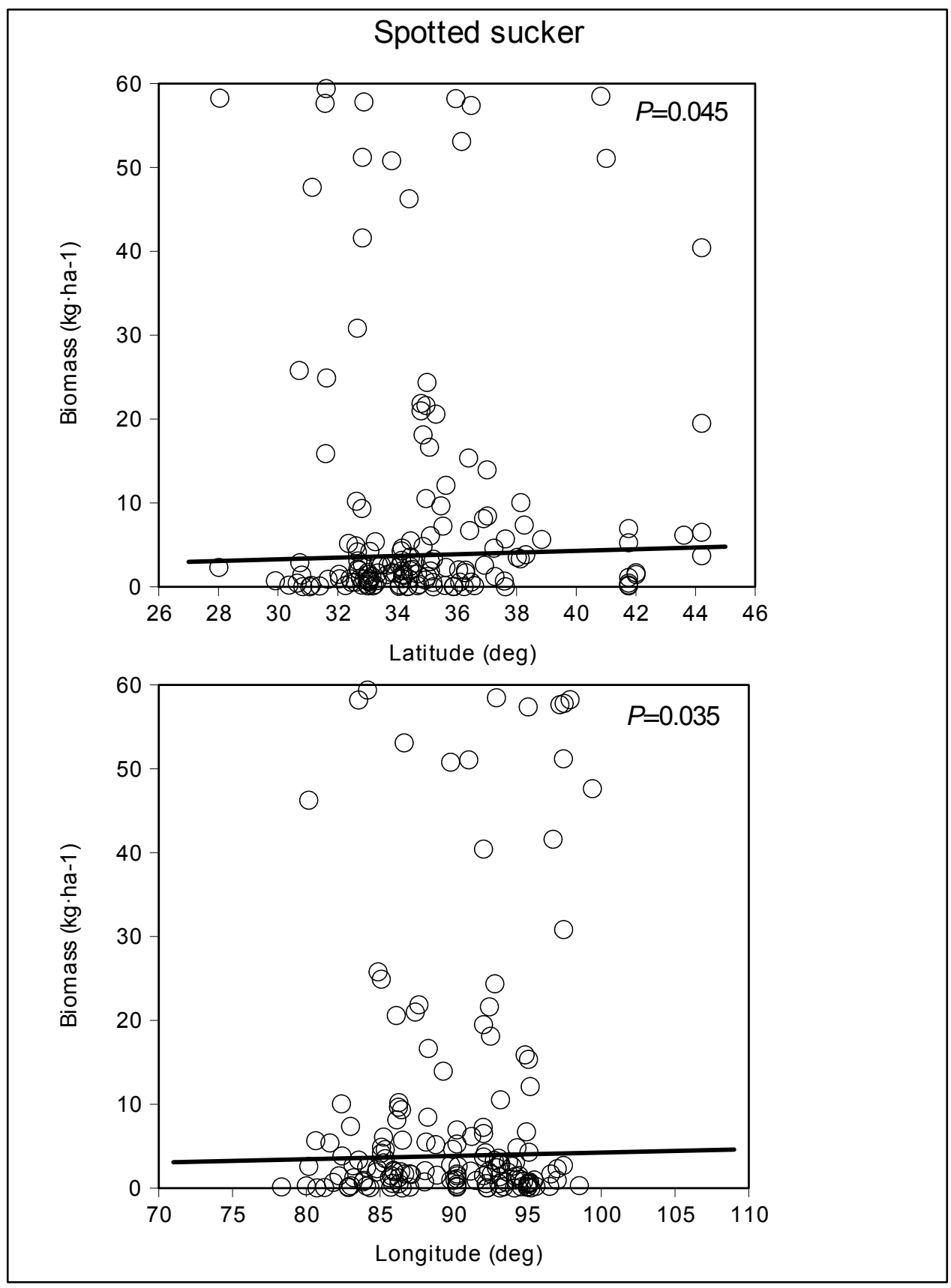

Figure 8. Linear regression analysis of biomass vs. latitude and longitude for spotted sucker from 428 reservoir and river systems in the United States. Systems are located from Texas east to Florida and north to the Ohio River, Missouri, and Kansas. $P$ values represent significance level of the individual regressions 


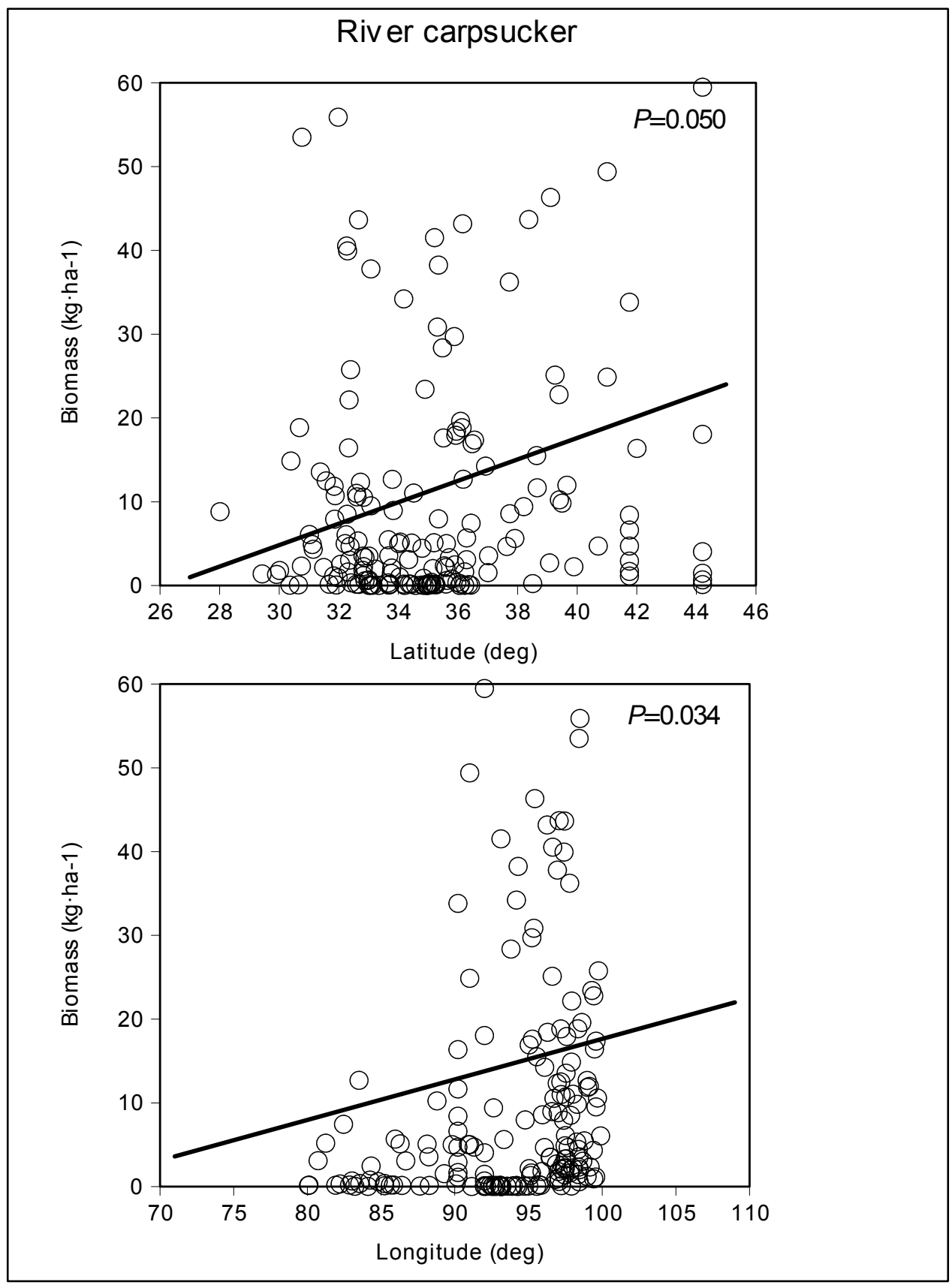

Figure 9. Linear regression analysis of biomass vs. latitude and longitude for river carpsucker from 428 reservoir and river systems in the United States. Systems are located from Texas east to Florida and north to the Ohio River, Missouri, and Kansas. $P$ values represent significance level of the individual regressions 


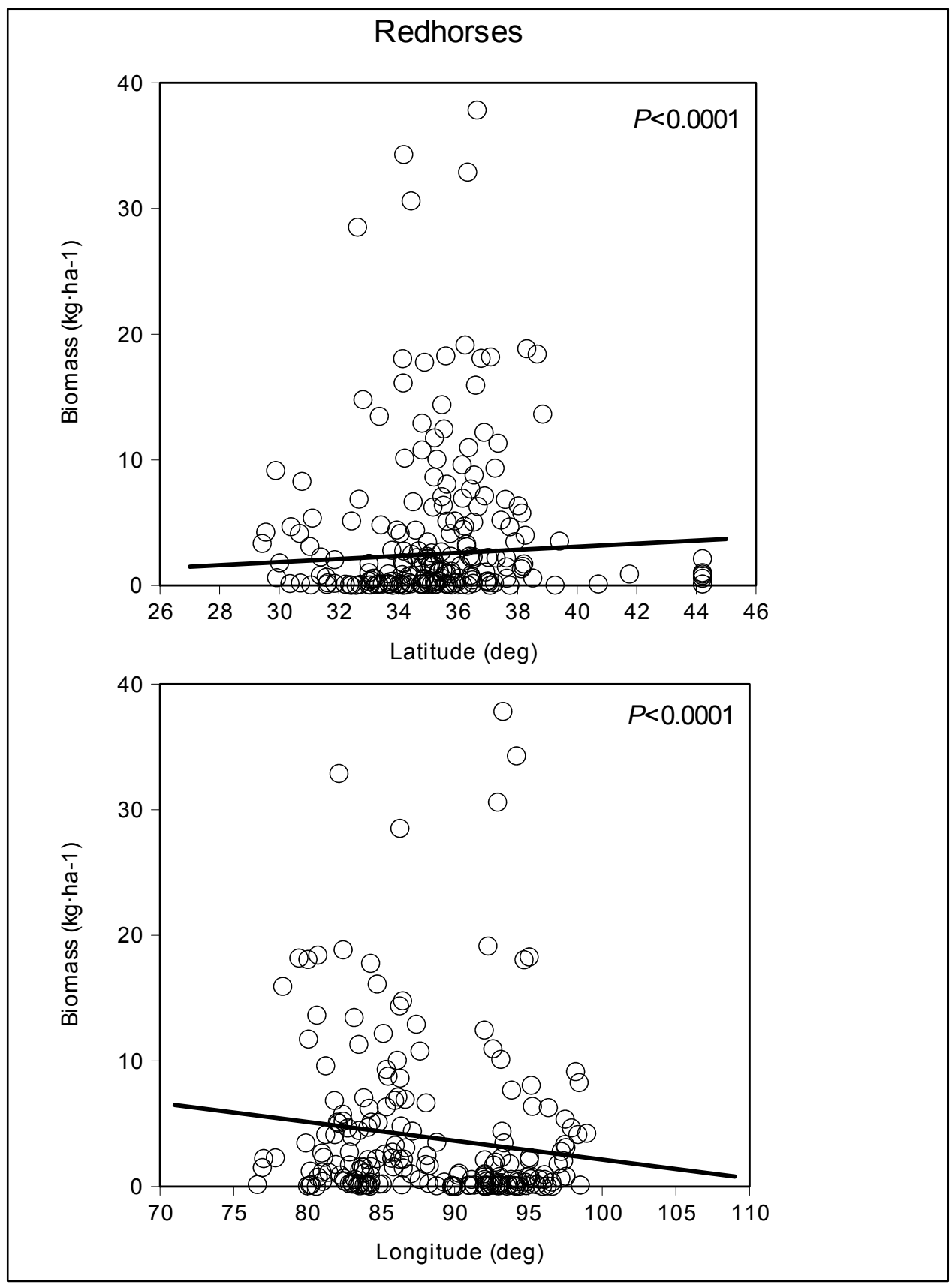

Figure 10. Linear regression analysis of biomass vs. latitude and longitude for redhorses from 428 reservoir and river systems in the United States. Systems are located from Texas east to Florida and north to the Ohio River, Missouri, and Kansas. P values represent significance level of the individual regressions 


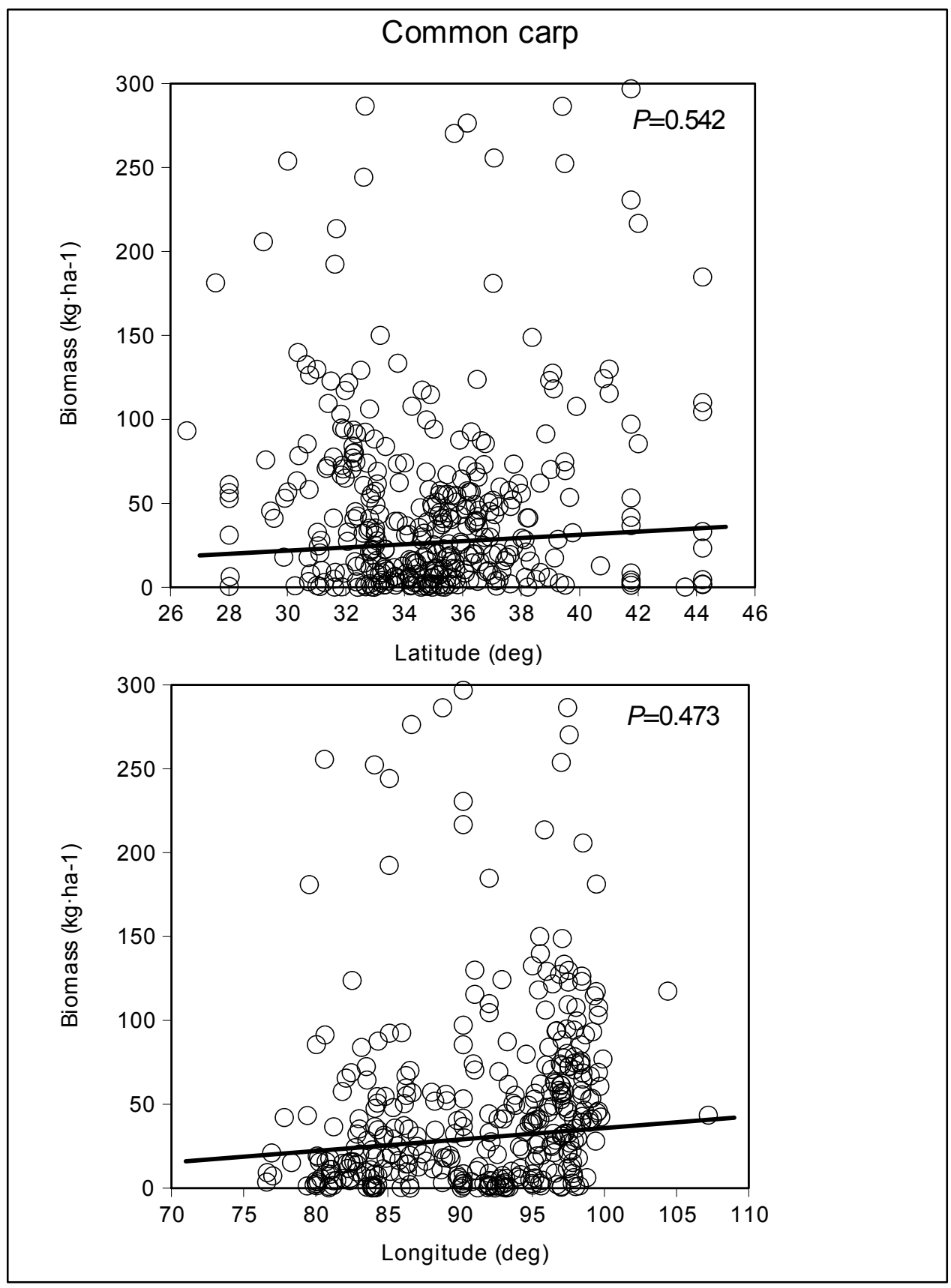

Figure 11. Linear regression analysis of biomass vs. latitude and longitude for common carp from 428 reservoir and river systems in the United States. Systems are located from Texas east to Florida and north to the Ohio River, Missouri, and Kansas. $P$ values represent significance level of the individual regressions 


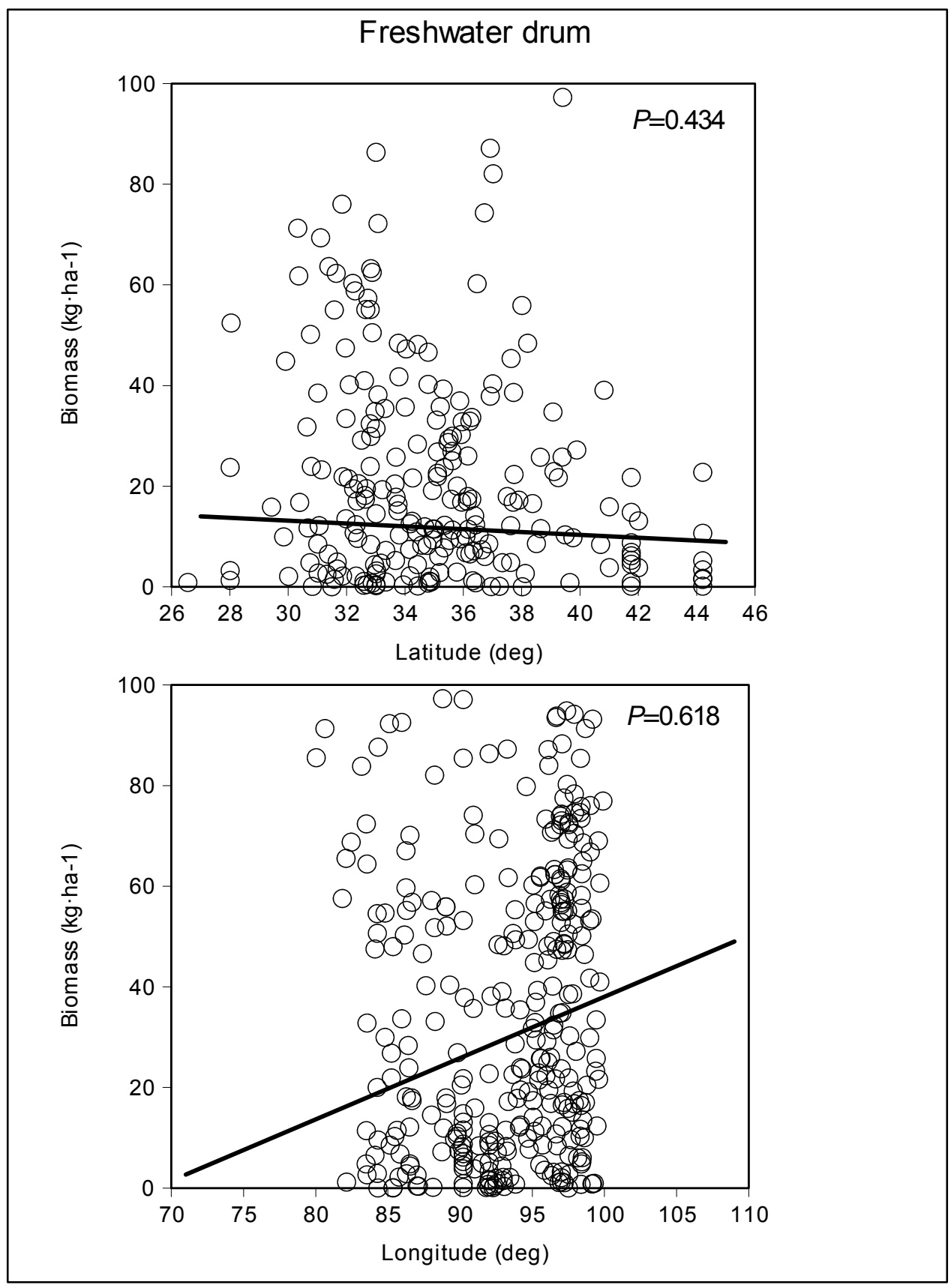

Figure 12. Linear regression analysis of biomass vs. latitude and longitude for freshwater drum from 428 reservoir and river systems in the United States. Systems are located from Texas east to Florida and north to the Ohio River, Missouri, and Kansas. P values represent significance level of the individual regressions 


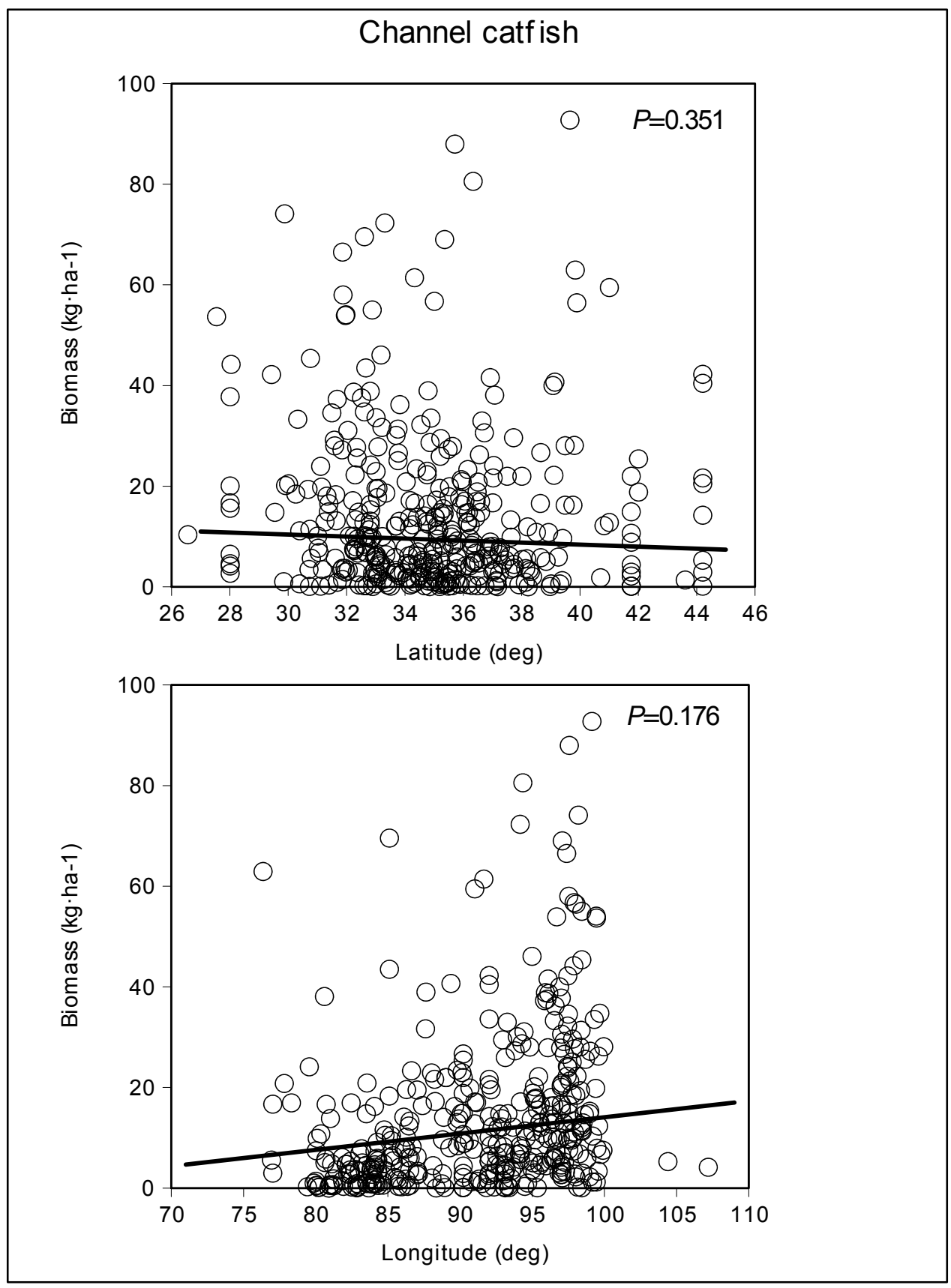

Figure 13. Linear regression analysis of biomass vs. latitude and longitude for channel catfish from 428 reservoir and river systems in the United States. Systems are located from Texas east to Florida and north to the Ohio River, Missouri, and Kansas. $P$ values represent significance level of the individual regressions 


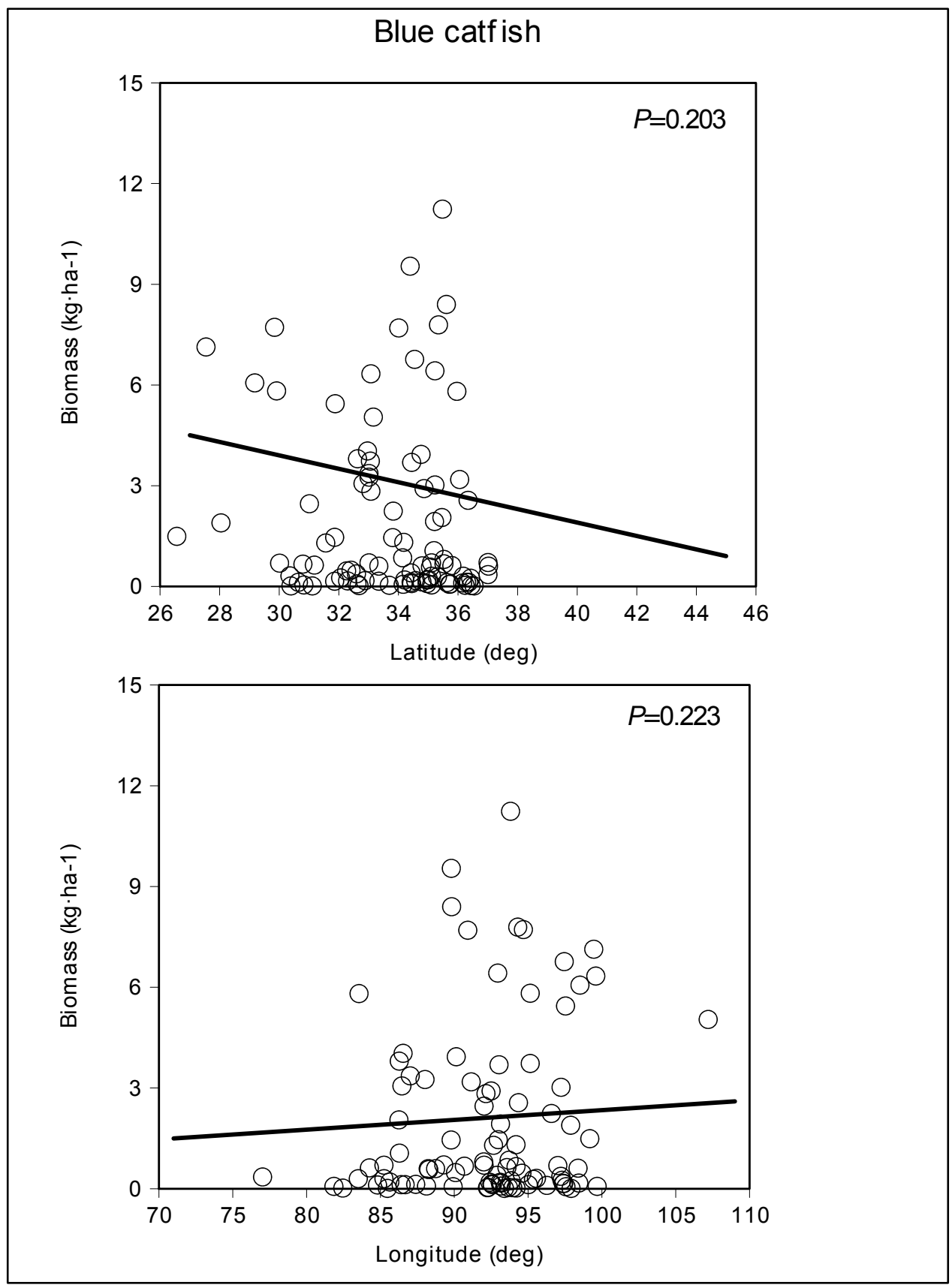

Figure 14. Linear regression analysis of biomass vs. latitude and longitude for blue catfish from 428 reservoir and river systems in the United States. Systems are located from Texas east to Florida and north to the Ohio River, Missouri, and Kansas. $P$ values represent significance level of the individual regressions 


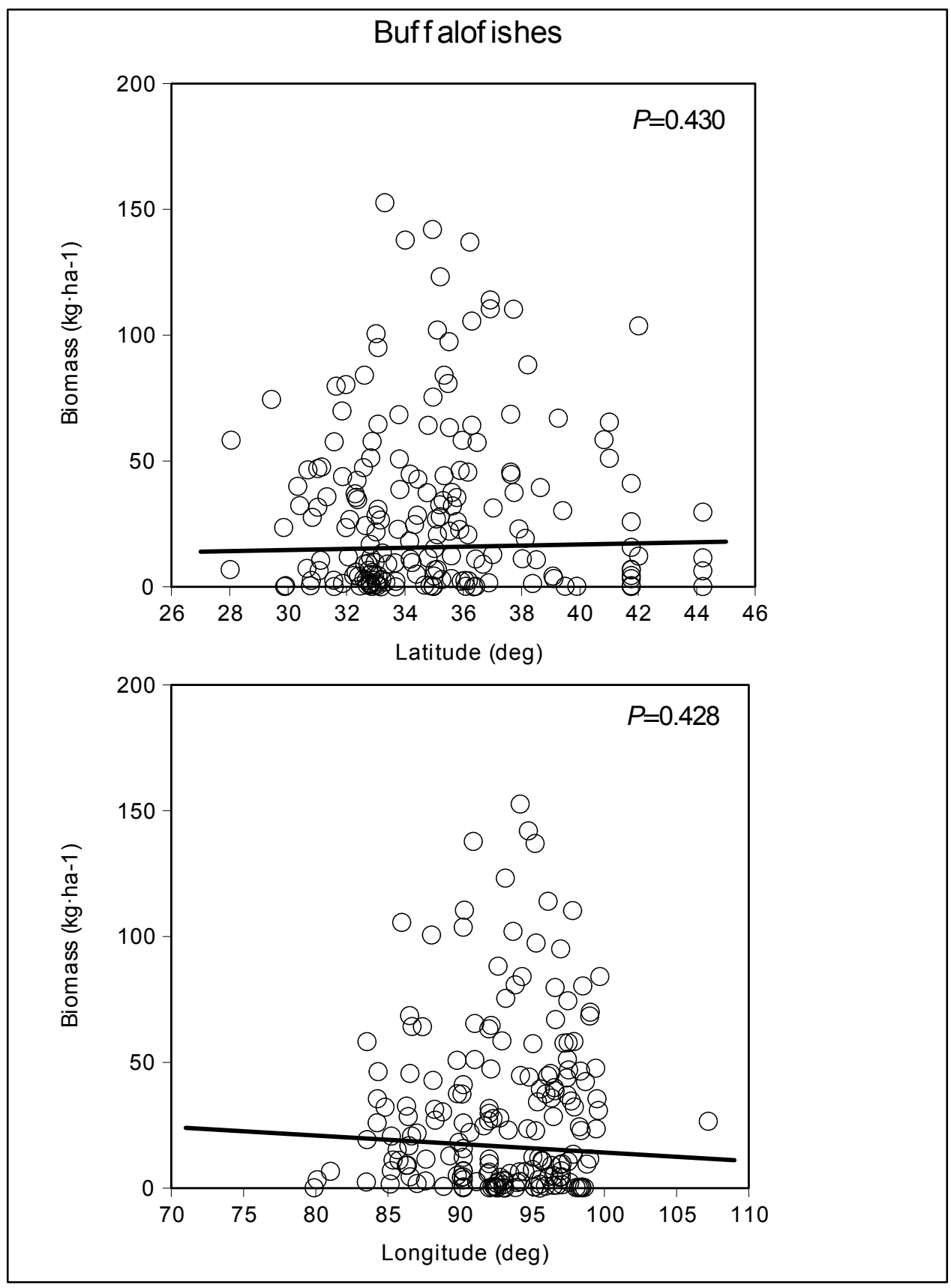

Figure 15. Linear regression analysis of biomass vs. latitude and longitude for buffalofishes from 428 reservoir and river systems in the United States. Systems are located from Texas east to Florida and north to the Ohio River, Missouri, and Kansas. $P$ values represent significance level of the individual regressions 


\begin{tabular}{|c|c|c|c|c|}
\hline \multicolumn{5}{|c|}{$\begin{array}{l}\text { Table } 5 \\
\text { Predicted Annual Food Consumption of Selected Fish Species for Each Study System } \\
\text { Estimated with Biomass-Based Model }\end{array}$} \\
\hline \multirow[b]{2}{*}{ System } & \multicolumn{4}{|c|}{ Estimated Food Consumption, as kg・ha ${ }^{-1} \pm \mathrm{SE}$} \\
\hline & Common carp & Freshwater drum & Channel catfish & Blue catfish \\
\hline Lower Mississippi River & $765( \pm 31)$ & $518( \pm 37)$ & $314( \pm 29)$ & $106( \pm 36)$ \\
\hline Upper Miss River Pool 26 & $978( \pm 32)$ & $453( \pm 38)$ & $269( \pm 30)$ & $63( \pm 38)$ \\
\hline Ohio River & $835( \pm 31)$ & $196( \pm 37)$ & $216( \pm 30)$ & $41( \pm 37)$ \\
\hline Upper Miss River Pool 13 & $1105( \pm 32)$ & $426( \pm 39)$ & $254( \pm 30)$ & $49( \pm 39)$ \\
\hline Lake Erie & $1010( \pm 32)$ & $111( \pm 38)$ & $218( \pm 30)$ & $24( \pm 38)$ \\
\hline Fox River & $1194( \pm 32)$ & $328( \pm 39)$ & $240( \pm 30)$ & $34( \pm 39)$ \\
\hline Upper Miss River Pool 4 & $1245( \pm 32)$ & $544( \pm 40)$ & $246( \pm 31)$ & $49( \pm 39)$ \\
\hline Lake Michigan & $1237( \pm 32)$ & $264( \pm 40)$ & $236( \pm 30)$ & $27( \pm 39)$ \\
\hline
\end{tabular}

\begin{tabular}{|c|c|c|c|c|}
\hline \multicolumn{5}{|c|}{$\begin{array}{l}\text { Table } 6 \\
\text { Predicted Annual Food Consumption of Selected Fish Species for Each Study } \\
\text { Estimated with Biomass-Based Model }\end{array}$} \\
\hline \multirow[b]{2}{*}{ System } & \multicolumn{4}{|c|}{ Estimated Food Consumption, as kg・ha-1 $\pm \mathrm{SE}$} \\
\hline & Buffalofishes & Spotted sucker & River carpsucker & Redhorses \\
\hline Lower Mississippi River & $726( \pm 41)$ & $252( \pm 38)$ & $100( \pm 39)$ & $90( \pm 33)$ \\
\hline Upper Miss River Pool 26 & $851( \pm 44)$ & $400( \pm 40)$ & $289( \pm 41)$ & $130( \pm 34)$ \\
\hline Ohio River & $1139( \pm 42)$ & $198( \pm 39)$ & $201( \pm 40)$ & $375( \pm 34)$ \\
\hline Upper Miss River Pool 13 & $929( \pm 45)$ & $480( \pm 41)$ & $495( \pm 42)$ & $160( \pm 35)$ \\
\hline Lake Erie & $1880( \pm 44)$ & $96( \pm 40)$ & $622( \pm 41)$ & $231( \pm 34)$ \\
\hline Fox River & $1121( \pm 45)$ & $406( \pm 42)$ & $774( \pm 43)$ & $284( \pm 35)$ \\
\hline Upper Miss River Pool 4 & $848( \pm 46)$ & $827( \pm 42)$ & $725( \pm 43)$ & $109( \pm 35)$ \\
\hline Lake Michigan & $1305( \pm 46)$ & $319( \pm 42)$ & $1001( \pm 43)$ & $461( \pm 35)$ \\
\hline
\end{tabular}

\section{Spatial Variation in Fish Communities}

Correspondence analysis (CA) explained 35 percent of the variation in fish communities on the first three ordination axes, which suggested strong spatial differences in fish communities. The ordering of sites along the first axis was strongly associated with longitude, whereas the second and third axes were associated with latitude. States of the southern United States tended to have greater axis- 1 and axis- 2 scores, whereas more northern states contained greater axis-1 and lower axis-2 scores (Figure 16). When plotting axis-3 versus axis-1 scores, only the latitudinal gradient was evident, with axis-3 scores exhibiting a slight inverse relationship to latitude (Figure 17). 


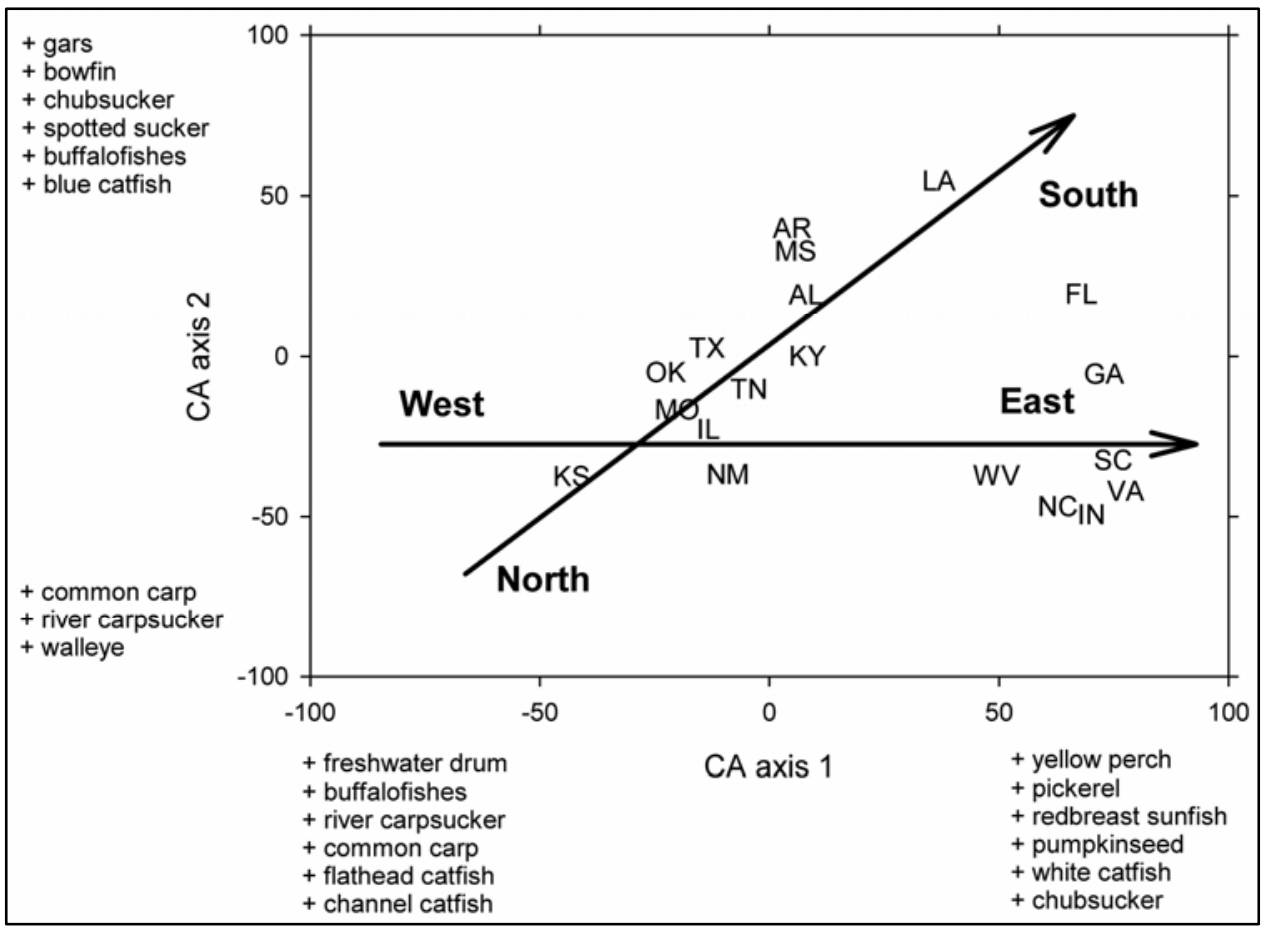

Figure 16. Scatterplot of axis-1 and axis-2 scores from correspondence analysis of fish biomass estimates from U.S. reservoir and river systems. Eigenvalues were 0.165 for axis 1 and 0.104 for axis 2, which together explained 31.8 percent of the variance in biomass. Axis- 1 and axis-2 scores were averaged by state and presented in lieu of showing all individual data points. Arrows indicate general direction of gradients. Species listed at ends of axes represent the rank order of greatest axis loadings

Several species were identified as contributing to the ordering of sites along ordination axes. Positive loadings on the first axis generally indicated that southeastern United States systems (e.g., Virginia, West Virginia, North and South Carolina, and Georgia) contained greater biomasses of yellow perch, white catfish, redbreast sunfish, pumpkinseed, and chubsuckers. The result with yellow perch seems counter-intuitive. However, yellow perch were widely introduced into upland reservoirs in the southeastern United States in the 1960s (Clugston, Oliver, and Ruelle 1978). Negative axis-1 loadings indicated greater biomasses of common carp, buffaloes, river carpsuckers, channel catfish, blue catfish, and freshwater drum in southern (e.g., Tennessee, Alabama, Mississippi, Texas, Kentucky, and Arkansas) and central (e.g., Missouri, Kansas, Oklahoma, and Illinois) U.S. systems. Axis-2 loadings mainly corroborated axis-1 loadings. Positive axis-2 loadings indicated greater biomasses of buffaloes, spotted sucker, freshwater drum, blue catfish, chubsuckers, gars, bowfins, and warmouth in more southern U.S. systems. Negative axis-2 loadings indicated greater biomasses of common carp, river carpsucker, and walleye in central U.S. systems. Overall, CA results suggested that central and southern U.S. systems contained greater biomasses of several species (e.g., common carp, buffaloes, freshwater drum, channel catfish, spotted sucker, and river carpsucker) likely to consume zebra mussels. 


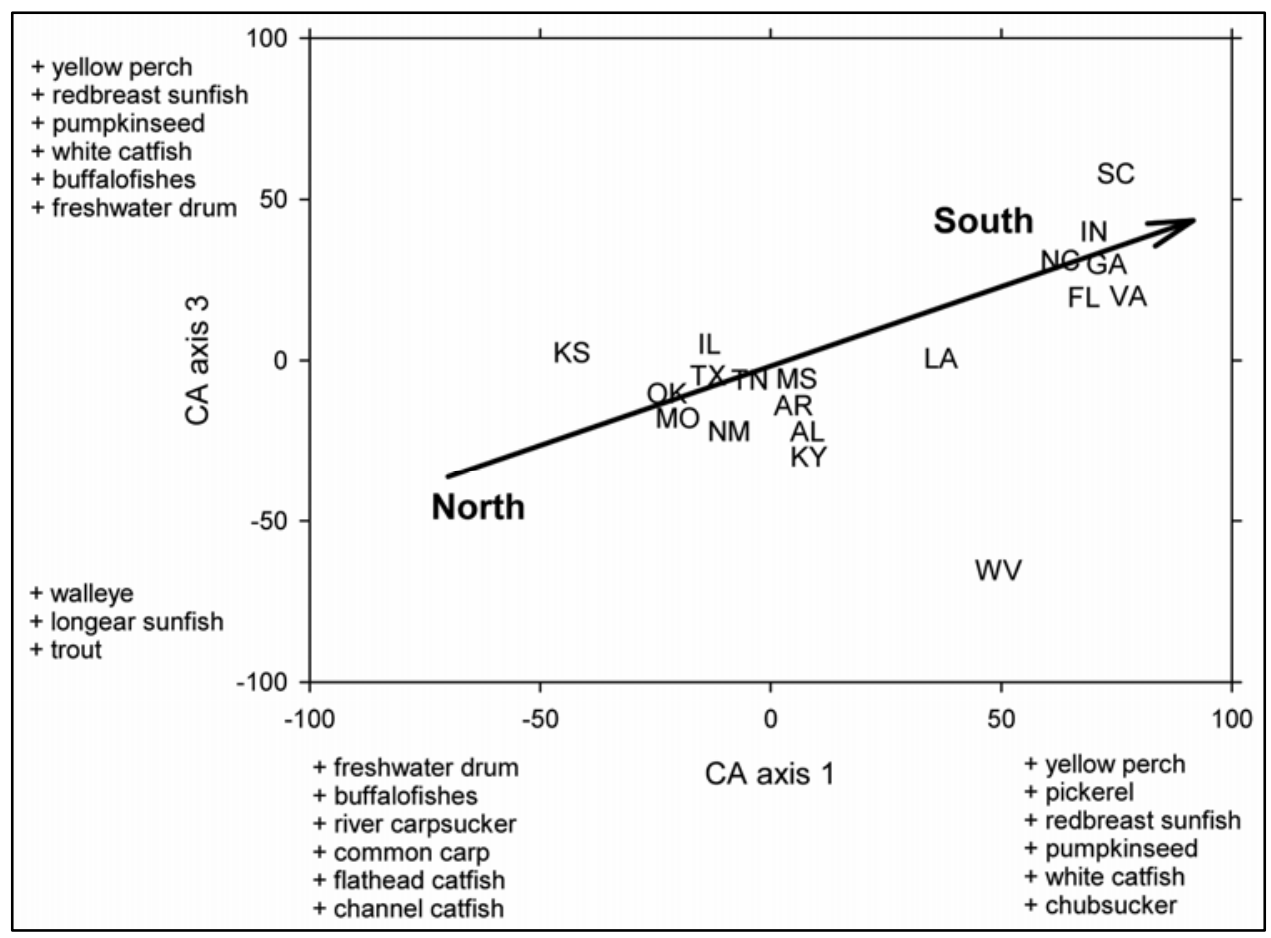

Figure 17. Scatterplot of axis-1 and axis-3 scores from correspondence analysis of fish biomass estimates from U.S. reservoir and river systems. Eigenvalues were 0.165 for axis 1 and 0.90 for axis 3 , which together explained 24.9 percent of the variance in biomass. Axis 1 and axis 3 scores were averaged by state and presented in lieu of showing all individual data points. Arrow indicates general direction of gradient. Species listed at ends of axes represent the rank order of greatest axis loadings

\section{Sensitivity Analyses}

\section{Food consumption model}

A sensitivity analysis of the parameters used in the food consumption model indicated that water temperature and slope of the evacuation rate model were least sensitive to error, and that stomach fullness, the intercept term to the evacuation rate model, and the water temperature exponent were most sensitive to error. Increases and decreases in water temperature yielded differences up to 2 percent in annual consumption at a +30 percent change (Table 7 ). Similar changes in the slope term of the evacuation model yielded differences up to 5 percent in annual consumption. Differences were greatest for the intercept term of the evacuation rate model, which yielded a -59 percent change in annual consumption when increased by 30 percent, and +146 percent change when decreased by 30 percent (Table 7). Similar changes in the temperature exponent term yielded +56 percent difference in annual consumption when the parameter was increased by 30 percent and a -34 percent change when the parameter was decreased 30 percent. However, because water temperature daily means were derived from at least several years of data (range 4 to 72 years per system, average 10 years), large errors in estimation were considered unlikely. 
Differences in stomach fullness were intermediate to these two parameters (Table 7).

\begin{tabular}{|c|c|c|c|c|c|}
\hline \multicolumn{6}{|c|}{$\begin{array}{l}\text { Table } 7 \\
\text { Proportional Changes in Annual Consumption Based on } \\
\text { Sensitivity Analysis of Food Consumption Modeling }\end{array}$} \\
\hline \multirow[b]{2}{*}{$\begin{array}{l}\text { Change } \\
\%\end{array}$} & \multirow[b]{2}{*}{$\begin{array}{l}\text { Water } \\
\text { Temperature }\end{array}$} & \multicolumn{3}{|c|}{ Food Consumption Model Parameters } & \multirow{2}{*}{$\begin{array}{l}\text { Evacuation Rate } \\
\text { Model } \\
\text { Temperature } \\
\text { Exponent }\end{array}$} \\
\hline & & $\begin{array}{l}\text { Stomach } \\
\text { Fullness }\end{array}$ & $\begin{array}{l}\text { Evacuation } \\
\text { Rate Model } \\
\text { Intercept }\end{array}$ & $\begin{array}{l}\text { Evacuation } \\
\text { Rate Model } \\
\text { Slope }\end{array}$ & \\
\hline 30 & 2.1 & 64.0 & -59.4 & 5.1 & 55.7 \\
\hline 20 & 0.8 & 40.8 & -45.2 & 3.3 & 33.9 \\
\hline 10 & 0.1 & 19.5 & -26.0 & 1.7 & 15.5 \\
\hline 5 & 0.05 & 9.5 & -14.0 & 0.8 & 7.4 \\
\hline 0 & -- & -- & -- & -- & -- \\
\hline-5 & -0.1 & -9.1 & 16.2 & -0.8 & -6.8 \\
\hline-10 & -0.3 & -17.8 & 35.1 & -1.6 & -13.1 \\
\hline-20 & -0.7 & -33.6 & 82.5 & -3.2 & -24.2 \\
\hline-30 & -1.2 & -47.7 & 147 & -4.8 & -33.6 \\
\hline
\end{tabular}

\section{Biomass-based model}

Sensitivity analysis of the biomass-based model indicated that all four parameters were sensitive to error. In the case of P-B ratio and GCE, potential error was considered unlikely because means and ranges of these variables used in modeling were based on numerous reported studies. The intercept term in the biomass-latitude regressions was most sensitive to error (Table 8). A 30-percent increase in this parameter yielded a +151 percent difference in annual consumption. Similarly, a 30-percent decrease resulted in a -59 percent change in consumption. Changes in the slope parameter yielded smaller differences in food consumption (Table 8). 


\begin{tabular}{|c|c|c|c|c|}
\hline \multicolumn{5}{|c|}{$\begin{array}{l}\text { Table } 8 \\
\text { Proportional Changes in Annual Consumption Based on } \\
\text { Sensitivity Analysis of Biomass-Based Food Consumption } \\
\text { Modeling }\end{array}$} \\
\hline \multirow{2}{*}{$\begin{array}{l}\text { Change } \\
\%\end{array}$} & \multicolumn{4}{|c|}{ Biomass-Based Model Parameters } \\
\hline & Intercept & Slope & P-B ratio & GCE \\
\hline 30 & 151 & 33.0 & 30 & -23.1 \\
\hline 20 & 84.1 & 20.6 & 19.9 & -16.6 \\
\hline 15 & 57.9 & 14.9 & 15 & -13.1 \\
\hline 10 & 35.5 & 9.7 & 10 & -9.1 \\
\hline 5 & 16.4 & 4.7 & 5 & -4.7 \\
\hline 0 & -- & -- & -- & -- \\
\hline-5 & -14.0 & -4.4 & -5 & 5.3 \\
\hline-10 & -26.0 & -8.5 & -10 & 11.1 \\
\hline-15 & -36.3 & -12.3 & -15 & 17.6 \\
\hline-20 & -45.1 & -16.0 & -20 & 25.0 \\
\hline-30 & -59.1 & -22.6 & -30.1 & 42.8 \\
\hline
\end{tabular}




\section{Discussion}

Simulations indicated food consumption by individual fishes was inversely related to latitude and, in effect, thermal regimes of the river and lake systems. This observation was consistent with four representative species likely to consume zebra mussels, namely, common carp, freshwater drum, channel catfish, and lake sturgeon. While rates of food consumption differed greatly among species, annual food consumption in the LMR, the southernmost system, was over 100 percent greater on average than that predicted for the northernmost system. Thus, fishes in northern U.S. waters appeared to have less inherent potential to impact zebra mussel populations than those in southern waters from the perspective of the rates of food likely to be consumed during typical years.

Latitudinal differences shown in this study may actually be more substantial in the wild than indicated by modeling. Average growth scenarios were derived from both northern and southern systems. However, it is likely that most northern fish populations would tend toward the slow-growth scenario (i.e., lower annual consumption) whereas more southern populations would fall somewhere between the average- and fast-growth scenarios (i.e., greater annual consumption). In the case of ages 3 to 4 common carp, fast-growth annual consumption in the LMR exceeded slow-growth annual consumption in northern Lake Michigan by over 600 percent. Similar proportional differences were observed with the other species and cohorts. Exceptions would likely exist in that growth and metabolic demands of fishes in some northern rivers and lakes would be more similar to that observed in many southern systems. However, generally speaking, it is likely that food consumption by fishes in most southern rivers and lakes would exceed most comparable northern waters by more than 100 percent during typical years. Although simulated food consumption by individual fishes was consistently greater at lower latitudes, the biomass of a species in a particular system determines its potential to impact zebra mussels. Multivariate analysis indicated standing crop or biomass of fish communities changed across both latitudinal and longitudinal gradients. Central and southern United States (i.e., Missouri, Kansas, Oklahoma, Kentucky, Tennessee, and Arkansas) fish communities tended to have greater biomasses of common carp, ictalurid catfishes, buffalofishes, carpsuckers, freshwater drum, and redhorses. All of these species have been documented as zebra mussel predators (French and Bur 1993; Tucker et al. 1996; Marsden 1997; Molloy et al. 1997; Morrison, Lynch, and Dabrowski 1997), have likely potential to consume zebra mussels based on mouthparts (French 1997), or have been reported as molluscivores. The lack of comprehensive biomass data from extreme northern United States systems with high zebra mussel densities (e.g., Wisconsin, Michigan, New York, 
and the Great Lakes) precluded a more definitive analysis. However, systems in these regions generally support greater biomasses of percids, esocids, and salmonids and lower biomasses of species like common carp, freshwater drum, catfishes, and catostomid suckers (i.e., 'rough' fishes) than comparable systems in the central and southern U.S. (Loftus and Regier 1972; Leach and Nepszy 1976; Lee et al. 1980). Although total fish biomass may not change appreciably across latitudes, the biomass contributed by species likely to consume zebra mussels may change. Thus, from the composition of resident fish communities, more northern communities appear to have less potential to impact zebra mussel populations by predation than their southern United States counterparts. In addition, greater biomasses of rough fishes in central and southern United States waters may be helping to curb expansion of zebra mussels into the lower Mississippi River and its tributaries.

Despite the multivariate findings, biomass-based estimates of food consumption were inconsistent with the hypothesis that lower biomasses of fishes that prey on zebra mussels in northern waters might have implications over control of zebra mussel densities. Though predicted food consumption of whole fish communities decreased by 21 percent between the LMR (southernmost system) and northern Lake Michigan (northernmost system), predicted cumulative consumption of the eight target species increased by 69 percent on average between the same systems. Increases in food consumption predicted from modeling for common carp (62 percent), buffalofishes (80 percent), spotted sucker (27 percent), redhorses (412 percent), and river carpsucker (901 percent) contributed most to this observation. Large proportional changes observed for river carpsucker and redhorses were based on much lower levels of biomass and consumption than those predicted for common carp and buffalofishes.

Because few biomass estimates were available for northern systems, we believe that fish biomass and food consumption estimates may have been overestimated. Latitudes for northern Lake Michigan, UMR Pool 4, Fox River, and eastern Lake Erie were the extreme end of the range of latitudes used to generate models. Thus, biomass-based food consumption may have been overestimated for these systems as a result of imprecise estimates of biomass. Though exceptions certainly exist for many northern lakes and rivers, greater biomasses of common carp, freshwater drum, catfishes, buffalofishes, and other catostomids indicated from modeling are not generally known from more northern systems where zebra mussels are abundant. In 10 river systems in Ohio, Sanders et al. (1999) reported that freshwater drum and channel catfish were relatively minor components of the fish community $(<5$ percent in terms of weight), especially in rivers draining into the Great Lakes. Similarly, Nelson and Smith (1981) categorized both channel catfish and freshwater drum as minor constituents of the fish community in a Michigan river. Conversely, common carp abundances were highly variable in these same systems, comprising as much as 70 percent or as little as 5 percent of the total fish biomass (Nelson and Smith 1981; Sanders et al. 1999). In the Great Lakes, where the greatest zebra mussel densities have been reported, fish communities are dominated by salmonids, percids, alewife Alosa pseudoharengus, and smelt Osmerus mordax (Stewart, Kitchell, and Crowder 1981; Jude and Leach 1999). Warmwater fishes tend to be a minor part of the fish community, though Lake Erie may be an exception (Leach and Nepszy 1976). Rivers and streams in Wisconsin are typically 
coolwater in most areas and contain greater abundances of smallmouth bass Micropterus dolomieu, sunfishes Lepomis spp., salmonids, and esocids, though some systems in the southern region of the state tend to have more warmwater assemblages (Wisconsin Dept. Natural Res., unpublished data). Though many of our target species are resident to these areas, their biomasses generally do not approach the levels observed in more southern and central U.S. waters. Collectively, findings from other studies support our contention of lower biomasses of species likely to impact zebra mussels in more northern systems, though modeling only partially supports this conclusion because of data limitations.

A useful application based upon our modeling efforts would be to assess how much biomass is needed to maintain a given level of food consumption across different systems. It is worth noting that food consumption modeling indicated a 100-percent increase in the rates of food consumed in the LMR compared to northern Lake Michigan (assuming average growth). Thus, if food consumption and biomass are assumed to be related in a 1:1 fashion, approximately twice the fish biomass would be needed in northern Lake Michigan to maintain the same level of population-level food consumption as in the LMR. This conclusion assumes average growth in both systems, so actual estimates may be greater or lesser. We compared predicted biomasses versus required biomass using this 1:1 biomass-food consumption ratio as a guideline. Because total fish biomass declined slightly with latitude, results suggested that northern Lake Michigan contained only about one-third of the biomass required to maintain the same level of food consumption as in the LMR (Figure 18). Proportional differences with the other study systems were smaller in magnitude and directly related to latitude. Predicted biomass increases in northern Lake Michigan for common carp (62 percent) and spotted sucker (27 percent) did not approach 100 percent (i.e., doubling of biomass), though buffalofishes (80 percent) did (Figure 19). Biomass increases predicted for river carpsucker (901 percent) and redhorses (408 percent) far exceeded 100 percent. However, biomass levels of these species were far less than common carp or buffalofishes and would be of less consequence in terms of net predation impacts by the whole fish community. Thus, several key species of fishes may lack the required biomass in more northern latitudes to impact zebra mussels the same levels observed in southern U.S. waters.

Although limitations of our data sets and methodologies certainly exist, previous studies lend support to our findings. The role of predators in freshwater communities is complex and controversial (e.g., Thorp 1986), but previous studies indicate that predators may significantly impact dreissenid populations. Studies in European rivers and lakes (e.g., de Nie 1982; Daoulas and Economids 1984; Draulens 1984; Smit et al. 1993) suggested that vertebrate predators may be responsible for keeping dreissenid densities below 3,000 mussels $\cdot \mathrm{m}^{-2}$ compared to densities in the Hudson (approximately 30,000 mussels $\cdot \mathrm{m}^{-2}$ ) and Ohio ( $\leq 40,000$ mussels $\cdot \mathrm{m}^{-2}$ ) Rivers (Thorp, Delong, and Casper 1998). Thorp, Delong, and Casper (1998) also indicated that resident fishes impacted zebra mussels but that impacts were greater among lower-density populations. Given the 100-percent or greater increase in food consumption in the LMR compared to northern Lake Michigan (depending on the growth scenario used), the lower 
densities of zebra mussels in southern U.S. waters may be consistent with the increased predation impacts of fish communities in those waters. Thus, fishes in more southern U.S. waters may have a competitive edge in controlling or restricting zebra mussel populations because of the bioenergetic advantages not possible in more northern rivers and lakes.

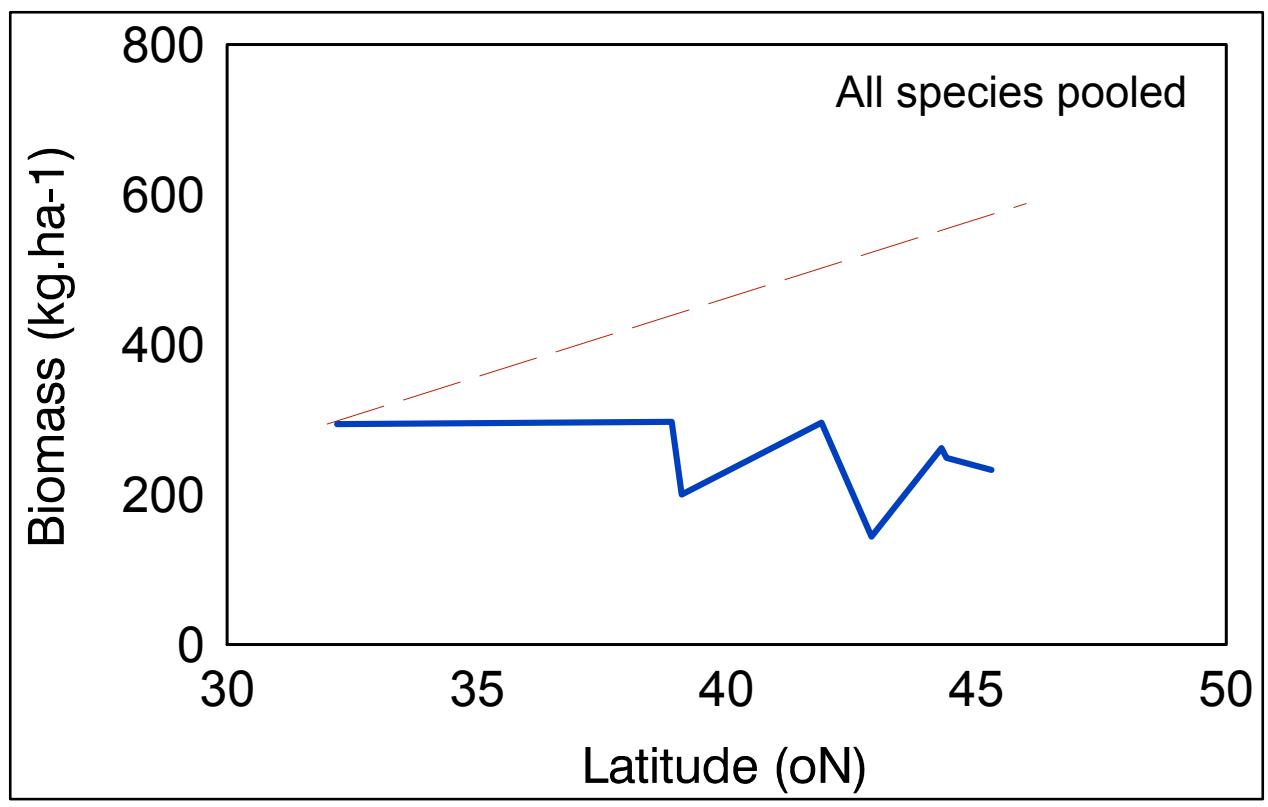

Figure 18. Comparison of predicted total fish biomass versus latitude curves (solid lines) and biomass required to maintain consumption at levels estimated for the lower Mississippi River using the Eggers model (dashed lines)

Our results were also consistent with previous in situ studies despite differing approach and differing scales of the evaluations. Thorp, Delong, and Casper (1998) reported from enclosure experiments that fishes had a stronger effect on zebra mussels in the UMR than the Ohio River. Furthermore, some evidence of size-selective predation existed in the UMR, presumably because fishes were able to more easily select larger mussels from less clumped, lower-density populations. Though they reported that zebra mussels were collected from the guts of several resident species (e.g, smallmouth buffalo, channel and flathead catfishes Pylodictis olivaris, and river carpsucker), they did not discuss the possibility that differing fish faunas between regions might have played a role in their results. Pitlo (1987) reported that mean fish biomass (as $\mathrm{kg} \cdot \mathrm{ha}^{-1}$ ) for several pools of the UMR (Illinois-Iowa and Wisconsin-Minnesota, $n=25$ ) were $84.7( \pm 18.9=1 \mathrm{SE})$ for common carp, $18.0( \pm 5.9)$ for river carpsucker, $7.2( \pm 3.7)$ for spotted sucker, $24.4( \pm 9.6)$ for buffalo fishes, $14.4( \pm 3.0)$ for channel catfish, and $13.0( \pm 5.9)$ for freshwater drum. Although biomass data were not available explicitly for the Ohio River mainstem, estimates from nearby Kentucky reservoirs in the same basin were $24.5( \pm 4.2)$ for common carp, $0.3( \pm 0.2)$ for river carpsucker, $3.0( \pm 0.9)$ for spotted sucker, $10.0( \pm 4.2)$ for buffaloes, $6.0( \pm 1.0)$ for channel catfish, and $8.2( \pm 4.5)$ for freshwater drum. Assuming biomass estimates (and resultant biomass-based food consumption) in the Ohio 
River mainstem are at least somewhat comparable to those of nearby reservoirs, differences in the composition of fish communities, particularly large omnivorous species, may partially explain the differential results between the two study systems used by Thorp, Delong, and Casper (1998).

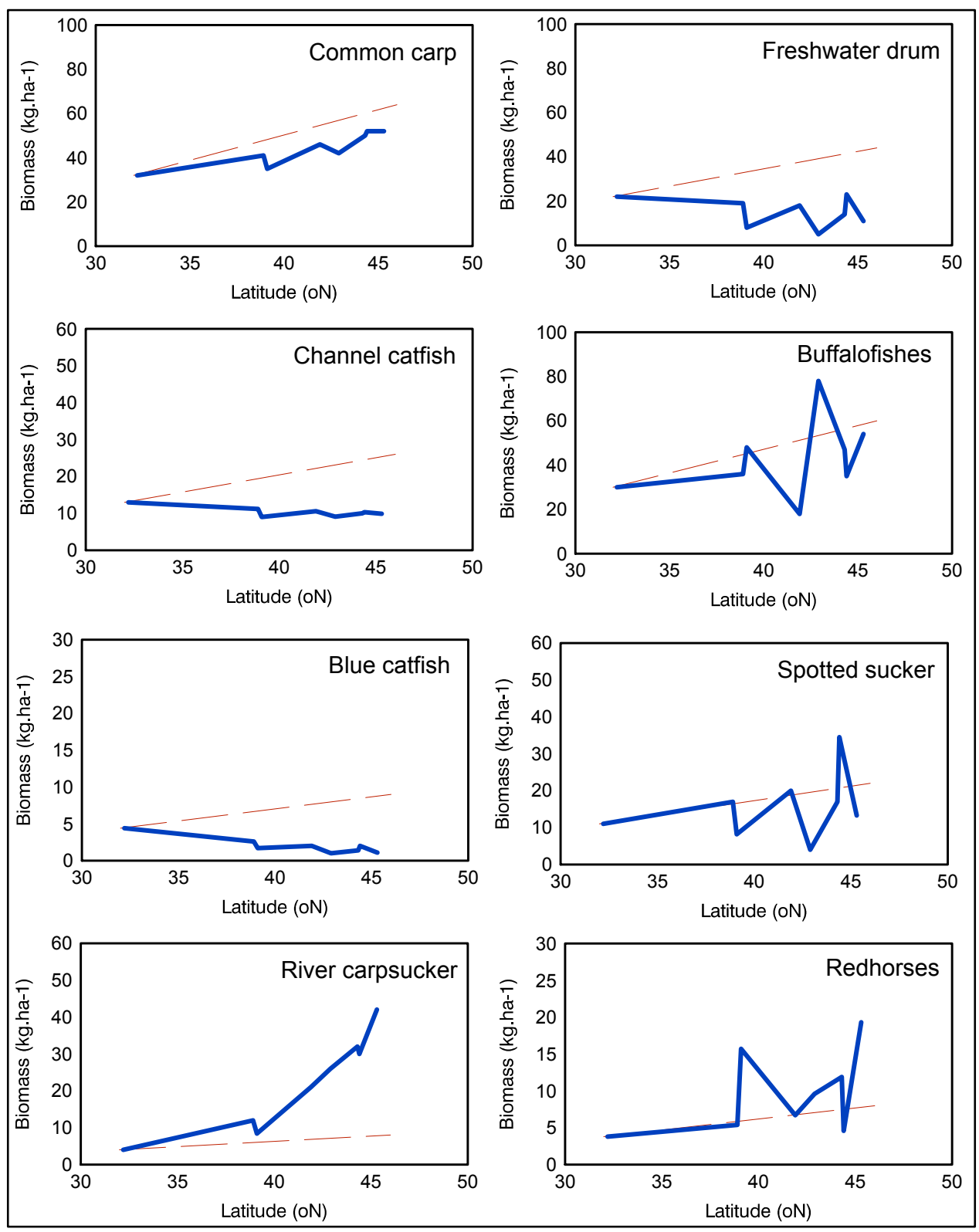

Figure 19. Comparison of predicted biomass versus latitude curves (solid lines) and biomass required to maintain consumption at levels estimated for the lower Mississippi River using the Eggers model (dashed lines)

An interesting observation suggested from our modeling was the tremendous potential that may exist with lake sturgeon as a biological control agent for zebra mussels. Historically, lake sturgeon were found throughout the Mississippi River Valley and Great Lakes region. Overfishing and habitat degradation reduced populations to extinction in many areas by the year 1900. However, though 
sturgeon stocks are still declining worldwide (Billard and Lecointre 2001), recent conservation efforts in the United States have reestablished viable lake sturgeon populations in some areas of the Great Lakes. Given its large size, longevity, and fairly diverse feeding habits, rapidly growing lake sturgeon populations may begin to significantly impact zebra mussels in the near future. Other sturgeon species inhabiting the Mississippi River may also affect zebra mussel populations, but at lower levels than suggested for lake sturgeon because of their smaller size.

Other factors unrelated to fish predation are also important in regulating zebra mussels in southern U.S. waters. Zebra mussel invasions throughout North America have occurred more rapidly through interconnected waterways than in isolated natural lakes (Kraft and Johnson 2000). Given that most southern reservoirs are located on large rivers and are connected through the Mississippi River or its tributary rivers (e.g., Ohio, Missouri, Arkansas, Tennessee, Cumberland), southern U.S. waters are easily susceptible to zebra mussel invasion. However, southern river and lake systems are significantly warmer and more turbid which may hamper zebra mussel survival (Thorp et al. 1998; Allen, Thompson, and Ramcharan 1999). Zebra mussels thrived in temperate northern U.S. waters where summertime water temperatures usually do not exceed 27 to $28{ }^{\circ} \mathrm{C}$ (McMahon 1996). Aldridge, Payne, and Miller (1995) further indicated from laboratory experiments that survival without extensive mortality could occur at temperatures up to $32{ }^{\circ} \mathrm{C}$. However, Allen, Thompson, and Ramcharan (1999) reported from field studies in the LMR that, although annual growth was comparable to northern regions, the pattern of growth was not, with shell growth ceasing and tissue condition declining during July and August when water temperatures approached 29 to $30{ }^{\circ} \mathrm{C}$. During these midsummer periods, mussel mortality increased, especially for individuals $>15 \mathrm{~mm}$. They concluded that summer mortality was probable for zebra mussels in the LMR and that the extent would depend on the duration of extreme water temperatures, population size structure, and condition during the preceding spring. Zebra mussels are also less tolerant to anoxia than most North American bivalves and may be restricted to well-oxygenated rivers and epilimnetic zones of reservoirs and lakes (Matthews and McMahon 1994). Furthermore, zebra mussels have been more sensitive to drawdowns than either Asiatic clams (another exotic) or other unionids (Tucker et al. 1997). Thus, physical conditions and fish predation may work in concert to limit zebra mussel abundances and distribution in most southern waters. 


\section{References}

Aldridge, D. W., Payne B. S., and Miller, A. C. (1995). "Oxygen consumption, nitrogenous waste, and filtration rates of Dreissena polymorpha," Canadian Journal of Fisheries and Aquatic Sciences 52, 1761-1767.

Allen, Y. C., Thompson, B. A., and Ramcharan, C. W. (1999). "Growth and mortality rates of the zebra mussels," Canadian Journal of Fisheries and Aquatic Sciences 56, 748-759.

Armstrong, M. L., and Brown, A. V. (1983). "Diel drift and feeding of channel catfish alevins in the Illinois River, Arkansas," Transactions of the American Fisheries Society 112, 302-307.

Billard, R., and Lecointre, G. (2001). "Biology and conservation of sturgeon and paddlefish,” Reviews in Fish Biology and Fisheries 10, 355-392.

Boisclair, D., and Leggett, W. C. (1988). "An in situ experimental evaluation of the Elliott and Persson and the Eggers model for estimating fish daily ration,” Canadian Journal of Fisheries and Aquatic Sciences 45, 138-145.

Brett, J. R., and Groves, T. D. D. (1979). "Physiological energetics.” Fish physiology. Vol 8. W. S. Hoar, D. J. Randall, and J. R. Brett, ed., Academic Press, New York, 279-353.

Carlander, K. D. (1969). Handbook of freshwater fishery biology. Vol 1. Iowa State Univ. Press, Ames, IA. . (1977). Handbook of freshwater fishery biology. Vol 2. Iowa State Univ. Press, Ames, IA. . (1997). Handbook of freshwater fishery biology. Vol 3. Iowa State Univ. Press, Ames, IA.

Clugston, J. P., Oliver, J. L., and Ruelle, R. (1978). "Reproduction, growth, and standing crops of yellow perch in southern reservoirs," American Fisheries Society Special Publication 11, 89-99.

Cobb, S. P., Pennington, C. H., Baker, J. A., and Scott, J. E. (1984). "Fishery and ecological investigations on main stem levee borrow pits along the lower Mississippi River," U.S. Army Corps of Engineers, Lower Mississippi River Environmental Program - Report 1, Vicksburg, MS. 
Daoulas, C. C., and Economidis, P. S. (1984). "The feeding of Rutilus rubilio in Lake Trichonis, Greece,” Cybium 8, 29-38.

DeMauro, R. A., and Miranda, L. E. (1990). "Food and growth of age-0 hybrid striped bass in Ross Barnett Reservoir, Mississippi," Proceedings of the Annual Conference of Southeastern Fish and Wildlife Agencies 44, 105-113.

de Nie, H. W. (1982). "A note on the significance of larger bivalve molluscs (Anodonta sp. \& Dreissena sp.) in the food of the eel (Anguilla anguilla) in Tjeukemeer,” Hydrobiologia 95, 307-310.

DeVries, D. R., and Frie, R. V. (1996). "Determination of age and growth," Fisheries Techniques. B. R. Murphy and D. W. Willis, ed., American Fisheries Society, Bethesda, MD, 483-512.

Draulens, D. (1984). "Sub-optimal mussel selection by tufted ducks Aythya fuligula: Test of a hypothesis,” Animal Behavior 32, 1192-1196.

Driscoll, M. P., and Miranda, L. E. (1999). "Diet ecology of yellow bass, Morone mississippiensis, in an oxbow of the Mississippi River," Journal of Freshwater Ecology 14, 477-486.

Eck, G. W., and Wells, L. (1983). "Biology, population structure, and estimated forage requirements of lake trout in Lake Michigan,” U.S. Fish \& Wildlife Service Paper 111.

Eggers, D. M. (1977). "Factors in interpreting data obtained by diel sampling of fish stomachs,” Journal of the Fisheries Research Board of Canada 34, 290294.

(1979). "Comments on some recent methods of estimating food consumption by fish,” Journal of the Fisheries Research Board of Canada 36, 1018-1019.

Eggleton, M. A. (2001). "Catfish feeding ecology and bioenergetics in a large river-floodplain ecosystem,” Ph.D. Diss. Mississippi State University, Mississippi State, MS.

Elliott, J. M., and Persson, L. (1978). "The estimation of daily rates of food consumption for fish,” Journal of Animal Ecology 47, 977-991.

French, J. R. P. (1997). "Pharyngeal teeth of the freshwater drum (Aplodinotus grunniens): A predator of the zebra mussel (Dreissena polymorpha)," Journal of Freshwater Ecology 12, 495-498.

French, J. R. P., and Bur, M. T. (1993). "Predation of the zebra mussel (Dreissena polymorpha) by freshwater drum in western Lake Erie," Zebra mussels: Biology, impacts, and control. T. F. Nalepa and D. W. Schloesser, ed., Lewis Publishers, Chelsea, MI., 453-464. 
French, J. R. P., and Love, J. G. (1995). "Size limitation on zebra mussels consumed by freshwater drum may preclude the effectiveness of drum in being a biological controller,” Journal of Freshwater Ecology 10, 379-383.

Hanson, P. C., Johnson, T. B., Schindler, D. E., and Kitchell, J. F. (1997). "Fish bioenergetics model 3.0,” University of Wisconsin, Sea Grant Institute, Madison, WI.

He, E., and Wurtsbaugh, W. A. (1993). “An empirical model of gastric evacuation rates for fish and an analysis of digestion in piscivorous brown trout,” Transactions of the American Fisheries Society 122, 717-730.

Hill, M. O., and Gauch, H. G. (1980). "Detrended correspondence analysis: An improved ordination technique,” Vegetatio 42, 47-58.

Idrisi, N., Mills, E. L., Rudstam, L. G., and Stewart, D. J. (2001). "Impact of zebra mussels (Dreissena polymorpha) on the pelagic lower trophic levels of Oneida Lake, New York,” Canadian Journal of Fisheries and Aquatic Sciences 58, 1430-1441.

Jude, D. J., and Leach, J. (1999). “Great Lake fisheries,” Inland fisheries management in North America. 2nd ed., C. C. Kohler and W. A. Hubert, ed., American Fisheries Society, Bethesda, MD, 623-664.

Keast, A., and Fox, M. G. (1992). "Space use and feeding patterns of an offshore fish assemblage in a shallow mesotrophic lake," Environmental Biology of Fishes 34, 159-170.

Kitchell, J. F., Stewart, D. J., and Weininger, D. (1977). “Applications of a bioenergetics model to yellow perch Perca flavescens and walleye Stizostedion vitreum," Journal of the Fisheries Research Board of Canada 34, 1922-1935.

Kraft, C. E., and Johnson, L. E. (2000). "Regional differences in rates and patterns of North American inland lake invasions by zebra mussels (Dreissena polymorpha)," Canadian Journal of Fisheries and Aquatic Sciences 57, 993-1001.

Leach, J. H. (1993). "Impacts of zebra mussels on the water quality and fish spawning reefs in western Lake Erie,” T. F. Nalepa and D. W. Schloesser, ed., Zebra mussels: Biology, impacts, and control. Lewis Publishers, Chelsea, MI, 381-397.

Leach, J. H., and Nepszy, S. J. (1976). "The fish community of Lake Erie,” Journal of the Fisheries Research Board of Canada 33, 622-638.

Lee, D. S., Gilbert, C. R., Hocutt, C. H., Jenkins, R. E., McAllister, D. E., and Stauffer, J. R., Jr. (1980). “Atlas of North American fishes,” North Carolina State Museum of Natural History, Raleigh, NC. 
Legendre, P., and Legendre, P. (1998). Numerical ecology. 2nd ed. Elsevier Science, Amsterdam.

Loftus, K. A., and Regier, H. A. (1972). "Introduction to other proceedings of the 1971 symposium on salmonid communities in oligotrophic lakes," Journal of the Fisheries Research Board of Canada 29, 613-616.

Lyons, J., and Magnuson, J. J. (1987). "Effects of walleye predation on the population dynamics of small littoral-zone fishes in a northern Wisconsin lake,” Transactions of the American Fisheries Society 116, 29-39.

Mackie, G. L., and Schloesser, D. W. (1996). "Comparative biology of zebra mussels in Europe and North America: An overview,” American Zoologist 36, 244-258.

Magoulick, D. D., and Lewis, L. C. (2002). "Predation on exotic zebra mussels by native fishes: Effects of predator and prey,” Freshwater Biology 47, 19081918.

Marsden, J. E. (1997). "Common carp diet includes zebra mussels and lake trout eggs,” Journal of Freshwater Ecology 12, 491-492.

Matthews, M. A., and McMahon, R. F. (1994). "The survival of zebra mussels (Dreissena polymorpha) and Asian clams (Corbicula fluminea) under extreme hypoxia," Proceedings of the 4th International Zebra Mussel Conference, March 7-10, 1994, Madison, WI.

Mayer, C. M., VanDeValk, A. J., Forney, J. L., Rudstam, L. G., and Mills, E. L. (2000). "Response of yellow perch (Perca flavescens) in Oneida Lake, New York, to the establishment of zebra mussels (Dreissena polymorpha)," Canadian Journal of Fisheries and Aquatic Sciences 57, 742-754.

McCune, B., and Mefford, M. J. (1999). "PC-ORD for Windows - Multivariate analysis of ecological data. Version 4.01.” MJM Software, Inc., Gleneden Beach, OR.

McMahon, R. T. (1996). "The physiological ecology of the zebra mussel, Dreissena polymorpha, in North America and Europe.” American Zoologist 36, 339-363.

Mills, E. L., Leach, J. H., Carlton, J. T., and Secor, C. L. (1993). “Exotic species in the Great Lakes: A history of biotic crises and anthropogenic introductions,” Journal of Great Lakes Research 19, 1-54.

Miranda, L. E., Hargreaves, J. A., and Raborn, S. W. (2001). "Predicting and managing risk of unsuitable dissolved oxygen in a eutrophic lake," Hydrobiologia 457, 177-185.

Molloy, D. P., Karatayev, A. Y., Burlakova, L. E., Kuradina, D. P., and Lareuelle, F. (1997). "Natural enemies of zebra mussels: Predators, parasites, and ecological competitors,” Reviews in Fisheries Science 5, 27-97. 
Morrison, T. R., Lynch, W. E., Jr., and Dabrowski, K. (1997). "Predation on zebra mussels by freshwater drum and yellow perch in western Lake Erie," Journal of Great Lakes Research 23, 177-189.

Nalepa, T. F., and Schloesser, D. W. (1993). "Zebra mussels: Biology, impacts, and control.” Lewis Publishers, Chelsea, MI.

Nelson, D. D., and Smith, D. W. (1981). "Rotenone fisheries survey of the Grand River,” Michigan Department of Natural Resources, Fisheries Division, Technical Report No. 81-3, Ann Arbor, MI.

Neves, R. L. (1981). "Fish production in warmwater streams.” Warmwater Streams Symposium, L. A. Krumholz, ed., American Fisheries Society, Bethesda, MD, 356-363.

Ney, J. J. (1993). "Bioenergetics modeling today: Growing pains and the cutting edge,” Transactions of the American Fisheries Society 122, 736-748.

Palmer, M. W. Ordination Methods for Ecologists. Department of Botany, Oklahoma State University, Stillwater, OK. www.okstate.edu/artsci/botany/ordinate.

Pitlo, J., Jr. (1987). "Standing stock of fishes in the upper Mississippi River," Upper Mississippi River Conservation Commission - Fisheries Technical Section. 28 pp.

Raborn, S. W. (2000). "An evaluation of feeding interactions among dominant piscivorous fishes in a southeastern reservoir,” Ph.D. diss., Mississippi State University, Mississippi State, MS.

Ram, J. L., and McMahon, R. F. (1996). "Introduction: The biology, ecology, and physiology of zebra mussels,” American Zoologist 36, 239-243.

Richardson, W. B., and Bartsch, L. A. (1997). "Effects of zebra mussels on food webs: Interactions with juvenile bluegill and water residence time,” Hydrobiologia 354, 141-150.

Robinson, J. V., and Wellborn, G. A. (1988). "Ecological resistence to the invasion of a freshwater clam, Corbicula fluminea: Fish predation effects," Oecologia 77, 445-452.

Roell, M. J., and Orth, D. J. (1993). "Trophic basis of production of streamdwelling smallmouth bass, rock bass, and flathead catfish in relation to invertebrate bait harvest," Transactions of the American Fisheries Society 122, 46-62.

Sanders, R. E., et al. (1999). "The frequency of occurrence and relative abundance of Ohio stream fishes,” Ohio Biological Survey Notes 2, 53-62. 
Smit, H., de Vaate, A. bij, Reeders, H. H., van Nes, E. H., and Noordhuis, R. (1993). "Colonization, ecology, and positive aspects of zebra mussels (Dreissena polymorpha) in the Netherlands.” Zebra mussels: Biology, impacts, and control. T. F. Nalepa and D. W. Schloesser, ed., Lewis Publishers, Chelsea, MI.

Stewart, D. J., Kitchell, J. F., and Crowder, L. B. (1981). "Forage fishes and their salmonid predators in Lake Michigan," Transactions of the American Fisheries Society 110, 751-763.

Thorp, J. H. (1986). "Two distinct roles for predators in freshwater assemblages,” Oikos 47, 75-82.

Thorp, J. H., Alexander, J., Jr., Bukaveckas, B., Cobbs, G., and Bresko, K. (1998). "Responses of Ohio River and Lake Erie dreissenid mollusc populations to changes in temperature and turbidity," Canadian Journal of Fisheries and Aquatic Sciences 55, 220-229.

Thorp, J. H., Delong, M. D., and Casper, A. F. (1998). "In situ experiments on predatory regulation of a bivalve mollusc (Dreissena polymorpha) in the Mississippi and Ohio rivers,” Freshwater Biology 39, 649-661.

Tucker, J. K., Cronin, F. A., Soergel, D. W., and Theiling, C. H. (1996). "Predation on zebra mussels (Dreissena polymorpha) by common carp (Cyprinus carpio),” Journal of Freshwater Ecology 11, 363-372.

Tucker, J. K., Theiling, C. H., Janzen, F. J., and Paukstis, G. L. (1997). "Sensitivity to aerial exposure of system-wide drawdowns to manage zebra mussels in the Mississippi River,” Regulated Rivers: Research \& Management 13, 479-487.

Tytler, P., and Calow, P. (1985). Fish energetics: New perspectives. John Hopkins University Press, Baltimore, MD. 


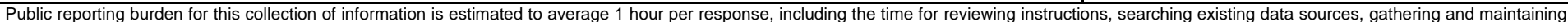

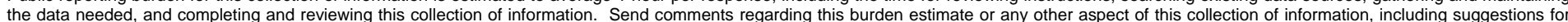

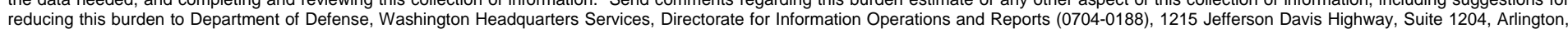

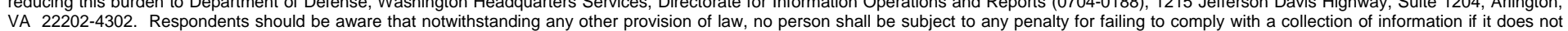
display a currently valid OMB control number. PLEASE DO NOT RETURN YOUR FORM TO THE ABOVE ADDRESS.

\begin{tabular}{l|c}
$\begin{array}{l}\text { 1. REPORT DATE (DD-MM-YYYY) } \\
\text { December } 2003\end{array}$ & $\begin{array}{c}\text { 2. REPORT TYPE } \\
\text { Final report }\end{array}$ \\
\hline
\end{tabular}

\section{TITLE AND SUBTITLE}

Potential for Predation by Fishes to Impact Zebra Mussels Dreissena polymorpha: Insight from Bioenergetics Models

3. DATES COVERED (From - To)

5a. CONTRACT NUMBER

5b. GRANT NUMBER

5c. PROGRAM ELEMENT NUMBER

5d. PROJECT NUMBER

5e. TASK NUMBER

5f. WORK UNIT NUMBER

8. PERFORMING ORGANIZATION REPORT NUMBER

ERDC/EL TR-03-22

U.S. Army Engineer Research and Development Center, Environmental Laboratory, 3909 Halls Ferry Road, Vicksburg, MS 39180-6199;

University of Oklahoma, Norman, OK 73069;

Mississippi State University, Department of Wildlife and Fisheries, Starkville, MS 39762

9. SPONSORING I MONITORING AGENCY NAME(S) AND ADDRESS(ES)

U.S. Army Corps of Engineers

Washington, DC 20314-1000

10. SPONSOR/MONITOR'S ACRONYM(S)

11. SPONSOR/MONITOR'S REPORT NUMBER(S)

\section{DISTRIBUTION / AVAILABILITY STATEMENT}

Approved for public release; distribution is unlimited.

\section{SUPPLEMENTARY NOTES}

\section{ABSTRACT}

Bioenergetic modeling provided insight into the potential for fishes to impact zebra mussel Dreissena polymorpha populations by predation across river and lake systems in eastern North America ( $13^{\circ}$ latitude $\times 12^{\circ}$ longitude). Food consumption modeling suggested that fishes in southern latitudes consumed up to 100 percent more food than those in northern systems. Much variation in food consumption was the result of differing water temperature regimes, which presumably dictated the bioenergetic demands of fishes. The potential for fishes to impact zebra mussels was also influenced by the standing crop of different species and the fish community as a whole. Fish community structures followed predictable patterns along both longitudinal and latitudinal gradients. Multivariate analyses indicated a tendency for central and southern U.S. systems to contain greater standing crops or biomasses of fishes likely to consume zebra mussels. Though analyses indicated northern systems had greater biomasses of some potential zebra mussel predators, net biomass increases of these species was not great enough to offset the decreases in food consumption due to cooler annual water temperatures. This study generally supports the premise that fishes in more southern (including central) U.S. waters have inherently greater potential to impact zebra mussels because of community composition and bioenergetics. Our simulations provide a partial explanation of why zebra mussel invasions have not been as rapid and widespread in southern U.S. waters compared to the Great Lakes region.

\begin{tabular}{ll} 
15. SUBJECT TERMS & Food consumption \\
Bioenergetics & Invasive species \\
Fish predation & Zebra mussels \\
\hline 16. SECURITY &
\end{tabular}

16. SECURITY CLASSIFICATION OF: Zebra mussels

\begin{tabular}{|l|l|l|}
\hline $\begin{array}{l}\text { a. REPORT } \\
\text { UNCLASSIFIED }\end{array}$ & $\begin{array}{l}\text { b. ABSTRACT } \\
\text { UNCLASSIFIED }\end{array}$ & $\begin{array}{c}\text { c. THIS PAGE } \\
\text { UNCLASSIFIED }\end{array}$ \\
\hline
\end{tabular}

\begin{tabular}{l|c|c|} 
17. LIMITATION & 18. NUMBER \\
OF ABSTRACT & OF PAGES & \\
& 52 & \\
& &
\end{tabular}

19a. NAME OF RESPONSIBLE PERSON

19b. TELEPHONE NUMBER (include area code) 